\title{
Parliamentary Representation and the Normalization of Radical Right Support ${ }^{1}$
}

\author{
Vicente VALENTIM, \\ European University Institute
}

\begin{abstract}
How do stigmatized political preferences become normalized? I argue that the parliamentary representation of the radical right normalizes radical right support. Radical right politicians breach established social norms. Hence their supporters have an incentive to conceal that support. When the radical right enters parliament, however, its voters are likely to perceive that their views have been legitimized, becoming more likely to display their private preferences. I use three studies to test this argument. Study 1 employs a regression discontinuity comparing the underreport of voting for radical right parties (RRPs) above and below thresholds of parliamentary representation. Study 2 compares how much individuals report liking RRPs in post-electoral surveys depending on interview mode. Study 3 employs a difference-in-differences that looks into the underreport of UKIP vote before and after entering parliament. The results support the argument and highlight the role of political institutions in defining the acceptability of behaviors in society.
\end{abstract}

I thank Tarik Abou-Chadi, Amalia Álvarez-Benjumea, Daniel Bischof, Alex Coppock, Elias Dinas, Vicky Fouka, Marta Fraile, Julian Garritzmann, Federica Genovese, Sara Hobolt, Rob Johns, Krzysztof Krakowski, David Laitin, Elli Palaiologou, Bilyana Petrova, Ana RuipérezNúñez, Julia Schulte-Cloos, and Zeynep Somer-Topcu for their very helpful comments on the manuscript. Previous versions of the paper were presented at the 2019 Conference of the Midwest Political Science Association, the 2019 Conference of the Italian Political Science Association, the EUI Political Behavior Colloquium, the Max Planck Institute for Research on Collective Goods, and the Institute for Social Sciences in Lisbon. This research was funded by the Portuguese Foundation for Science and Technology, Grant SFRH/BD/135089/2017.

\footnotetext{
${ }^{1}$ Replication materials and code can be found at Valentim (2020).
} 
In the Post War period, social norms were put in place in Western democracies against the expression of racism and prejudicial ideologies such as Fascism and Nazism (Rydgren 2005; Sniderman et al. 1991; Billig 1991). While certainly not disappearing, such views were increasingly regarded as socially undesirable, and individuals started concealing them or stating them in more symbolic, ambiguous ways (Billig et al. 1988; McConahay and Hough 1976). Recent years, however, have provided us with highly mediatic examples of individuals displaying these kinds of stigmatized behavior in public. For example, a number of protesters during the Charlottesville "Unite the Right" were seen displaying Swastikas. Some participants in the Chemnitz demonstration that took place in Germany in August 2018 were seen doing the Nazi salute. These anecdotes suggest that the set of acceptable behaviors changes over time, and that previously stigmatized can become more prevalent. What explains these changes?

This paper looks at the role of the parliamentary presence of radical right candidates and parties in normalizing previously sanctioned behavior. Radical right politicians openly defy established social norms (Mudde 2004, p. 554). For example, Björn Höcke, a politician for the radical right party Alternative for Germany (AfD), recently referred to the Berlin Holocaust memorial as a monument of shame. Similarly, French radical-right leader Jean-Marie Le Pen referred to the Holocaust as a "detail of history", and often complained that the French soccer team did not reflect French society because it included non-white players. Politicians from Hungarian party Jobbik have made a number of similar Anti-Semitic claims, and associated the Roma people - the country's largest minority — with parasitism.

Given their open defiance of norms against prejudice and racism, showing support for radical right politicians can come at the cost of social sanctions. Hence, their supporters have an incentive to falsify their preferences - i.e., to misrepresent views that breach established norms (Kuran 1995). The difficulties of accurately polling the electoral support for the radical right, which is often understated in polls, can be taken as an example of this preference falsification on the behalf of radical right voters. 
Bringing together insights from political behavior and social psychology, I argue that this situation is likely to change if radical right parties (RRPs) acquire parliamentary representation. There are two reasons why parliamentary representation is likely to normalize radical right support. On the one hand, elections can work as information shocks. They provide summary information on the true preferences of individuals in a society, which can reduce uncertainty as to how many other individuals support the party. Such information signals that many others do support the radical right, even if that may not be what one ought to do. Moreover, electoral success can signal that radical-right support is more pervasive than one had previously thought, which means that others are less likely to punish the expression of radical-right preferences. On the other hand, institutions signal set of behaviors that are acceptable in society. The fact that the radical right has parliamentary representation can make voters perceive that norms have shifted to make radical-right views less stigmatized. As a consequence, they can become more confident in publicly demonstrating support for the radical right, in a way that they would not have done had the party not made it to parliament.

Testing this argument with resource to comparative observational data is a difficult task because it requires distinguishing between individuals who are unwilling to show their support for the radical right and individuals who simply do not support it. In other words, one needs to be able to distinguish between revealed and true preferences of individuals, an imperative problem in the study of public opinion and voting behavior. I rely on three studies that follow different strategies to overcome this problem. In the first and third, I develop a measure of the stigmatization of RRPs, which is based on the share of the official vote for each party that is reported in post-electoral surveys. The reasoning behind this measure is that one can take the official vote for a party as a measure of the true underlying support for the party, and the reported support for that party in surveys as a measure of its revealed support in conditions of social pressure not to report radical right support. Consequently, the share of the official vote that is reported in post-electoral surveys can be taken as a measure of the appropriateness of reporting support for the radical right. 
In Study 1, I use comparative evidence to test how the parliamentary presence of an RRP affects this appropriateness. Using a regression discontinuity design (RDD) that takes advantage of legally established parliamentary thresholds as an exogenous source of variation, the analyses show that, for each ten individuals who voted for an RPP, four to five more (depending on model specification) were willing to tell the interviewer that they had done so if the party had narrowly made it to parliament than if it had narrowly failed to do so. I find no evidence that this effect is driven by any of four alternative explanations: a bandwagon effect; a difference in the characteristics of individuals who answer post-electoral surveys in the treatment and control group; a difference in the overall left-right placement of the party-system; or a difference in the level of extremism of RRPs in the control and treatment group.

Finally, when it comes to the mechanism, the analyses seem more compatible with the results being driven by the signaling role of political institutions than by an information shock. The effect seems to be stronger in elections with lower thresholds, against what one would expect according to the information shock mechanism. Supporting the institutional signaling mechanism, the effect is stronger for individuals whose interview was more distant from the election date. This suggest that individuals learn about the new norm over time, instead of changing their behavior immediately after the election — as one would expect according to the information shock mechanism.

Study 2 complements these findings by looking deeper into individual-level data. It takes advantage of the fact that some elections in the Comparative Study of Electoral Systems (CSES) include respondents interviewed in ways that forced an interaction with the interviewer (public modes), while others were interviewed in ways that did not force such interaction (private modes). I show that when an RRP is represented in parliament, individuals report liking it more in public modes of interview vis a vis private modes. The analyses further show that the effect is much stronger for right-wing individuals (as proxied by the ideology of the party they had voted for) then for left-wing individuals.

Finally, Study 3 tests whether the same results can be replicated by looking into 
the same party before and after it enters national parliament for the first time. It draws upon the case of one RRP that ran for several elections before entering parliament: the United Kingdom Independence Party (UKIP). Doing so also provides the advantage of replicating the analyses of Study 1 and Study 2 in a majoritarian system. The results of difference-in-differences (DiD) models show that, for each ten individuals that had voted for the party, two more were willing to tell their interviewer that they had done so after it made it to parliament. These results are not being driven by changes in the sociodemographic characteristics of UKIP voters before and after the party made it to parliament or by the good electoral result of UKIP in the 2014 election for the European Parliament.

The findings of the paper highlight how the presence of norm-breaching political actors in democratic institutions can lead to normative change. They also show how social norms affect individuals' decision of whether or not to publicly reveal their private political preferences.

\section{Literature on Consequences of Radical Right Success}

Previous research has shown radical right success to have a number of important consequences. In the first place, it can affect the strategy and ideology of the remaining parties and politicians. As a response to radical right success, the mainstream right can adopt more rightist positions (Bale 2003; Abou-Chadi 2016; Han 2015; Schain 2006; Abou-Chadi and Krause 2018). There is also some evidence of a similar effect on the mainstream left (Abou-Chadi and Krause 2018), although this finding is less consensual (Bale et al. 2010; Han 2015; Schain 2006).

Radical right success can also affect the set of issues that are discussed in the political debate. Extending an argument initially made in the U.S. context (Carmines and Stimson 1989; Riker 1986), the literature on party entrepreneurship has argued that the radical right can politicize new dimensions of political conflict (Hobolt and De Vries 2015). 
Entrepreneurship seems to be a profitable strategy, in that RRPs tend to reap electoral benefits from the politicization of new issues (De Vries and Hobolt 2012).

Finally, RRPs can also influence the attitudes and issue priorities of voters. The case study by Schain (2006) looks at how the success of the French National Front made French voters more focused on issues such as security and immigration. Similarly, focusing on issues of economic integration, De Vries and Edwards (2009) find cueing effects of extreme parties at both ends of the ideological continuum. In turn, Bischof and Wagner (2019) find that the parliamentary entry of an RRP leads to increased polarization, which they argue is due to both a legitimization and a backlash effect.

This legitimization effect is one that deserves careful empirical examination, so as to assess the extent to which voters more willing to perceive stigmatized views to be normalized as a consequence of the parliamentary success of RRPs. Doing so is complicated by the fact that one needs to distinguish between an individual's true preferences and the preferences they display in public, so as to measure the extent to which the parliamentary entry of an RRP can make individuals more confident in displaying previously stigmatized views. Drawing on experimental evidence Bursztyn, Egorov, and Fiorin (2017) show that after being shown data suggesting that Trump's election was given as certain in their state, individuals were more likely to report anti-immigration positions. Moreover, after being provided with this information, individuals that openly expressed such preferences were less negatively judged by others. This very valuable insight, however, has the problem of being confined to lab evidence from the U.S.. Given the difficult task of studying this effect with resource to observational data, no study to my knowledge has thus far engaged in that endeavor. That is the goal of this paper.

\section{Radical Right Politicians as Norm Defiers}

I argue that the parliamentary presence of radical right politicians and parties can normalize public expressions of support for the radical right. This argument builds on the 
social psychological concept of social norm, which can be defined as a "behavioral rule that (1) is known to exist and apply to a class of situations; and (2) is followed by individuals in a population on condition that a) it is believed that sufficiently many others follow it (empirical expectations), and b) it is believed that sufficiently many others believe the rule should be followed, and/or may be willing to sanction deviations from it (normative expectations)" (Bicchieri 2017, p. 66).

Previous empirical research has shown the impact of social norms on a number of behaviors. When provided with information about what others do or think should be done, individuals tend to change their actions to follow that norm. This finding is consistent across behaviors as disparate as reusing hotel room towels (Goldstein, Cialdini, and Griskevicius 2008), choosing ways of transport (Kormos, Gifford, and Brown 2015), or eating and drinking behavior (Pedersen, Grønhøj, and Thøgersen 2015; Rimal and Real 2005).

The influence of social norms has been shown to extend to political behavior as well, especially regarding the decision to vote or to abstain. Departing from the observation that voter turnout is often over-reported in surveys, Karp and Brockington (2005) show evidence suggesting that this is due to pressure to report the socially desirable answer. They find over-reports to be higher in contexts of higher turnout, where such social pressures should be stronger. Subsequent research has added to this finding by providing causal evidence of this relation. Using a field experiment, Gerber, Green, and Larimer (2008) find that sending messages to voters promising to advertise their turnout around their household or neighborhood significantly increases their propensity to vote. In digging deeper into the mechanism driving this effect, posterior studies have found that messages emphasizing expectations of high turnout seem to be more effective in increasing propensity to vote than messages emphasizing expectations of low turnout (Gerber and Rogers 2009) and that emotional appeals can also be very effective in making individuals behave in norm-conforming ways (Panagopoulos 2010).

Voter turnout, however, is not the only sort of political behavior that is likely to be 
affected by social norms. The extent to which individuals publicly display their support for a given party or candidate is also likely to be affected by normative expectations. They may fear that, in expressing a political preference that is contrary to the most commonly held opinion, they may incur in social sanctions such as isolation or career repercussions. For this reason, they may choose to remain silent instead of revealing their preferences (Noelle-Neumann 1974).

This paper draws upon a specific type of socially sanctioned political preference: support for radical-right politicians and candidates. These parties are, by nature, norm defiers (Mudde 2004, p. 554). Their xenophobic rhetoric openly opposes social norms against the derogatory treatment of minority groups. Following the de-legitimization of biological racism in the Post-War period (Rydgren 2005; Ignazi 1992), racism became increasingly regarded as socially undesirable in Western democracies of the 1970s and 1980s (Sniderman et al. 1991, p. 424). In other words, social norms emerged against the expression of those views (Billig et al. 1988; Billig 1991). The existence of these norms means that expressing one's support for the radical right may affect one's reputationa concern that may outweigh the utility one extracts from being true to their private preferences (Kuran 1987, pp. 644-645). This gives radical-right supporters an incentive to falsify their preferences to avoid the reputational costs of norm-breaching behavior.

I argue that parliamentary representation is one crucial channel through which radical right support can become normalized. There are two main mechanisms through which parliamentary representation could change social norms and thus bring about changes in the behavior of individuals. In the first place, elections can work as information shocks, providing an accurate depiction of how many others in one's society privately support the radical right. This sort of information can play a crucial in process of norm change. In its absence, even if many individuals privately support the party, they can be locked in a situation of pluralistic ignorance, in which many disagree with the norm in place but still abide by it because they are not aware that others also oppose it (Bicchieri 2017). The information provided by elections can help overcome this deadlock in two main ways. On the one hand, because voting is secret, individuals can freely express their true preferences 
(Kuran 1995). Electoral outcomes can thus provide individuals with crucial information about the prevalence of norm-breaching preferences within a community. Hence, elections can signal that, even if supporting the radical-right may not what ought to be done, many others do it. In situations such as these, individuals tend to follow what others do instead of what they think should be done (Bicchieri and Xiao 2009; Pedersen, Grønhøj, and Thøgersen 2015).

On the other hand, the information shock provided by elections can affect behavior by changing individual perceptions of how costly it is to reveal their true preferences. Norms affect behavior to the extent that one believes their social referents are likely to punish them for transgressing the norm. Realizing that a less-than-expected proportion of individuals supports the norm means that a lower number of individuals are likely to punish such transgressions, which lowers the costs of breaching the norm (Bicchieri and Mercier 2014).

Apart from working as an information shock, the parliamentary presence of the radical right can normalize radical-right support because representative and governing institutions can signal what kind of behaviors are normatively desirable in a society (Tankard and Paluck 2016, pp. 192-193). One particular way by which institutions can bring about normative change is by accommodating innovation in terms of the views or actors represented in them. In so doing, they can signal to individuals that social norms have moved in the direction of the innovation. Examples include the imposition of gender quotas for women in powerful political positions (Beaman et al. 2009) or quotas for stigmatized groups (Chauchard 2014), both of which made the views of the population more positive towards these social groups.

One might expect an analogous mechanism to operate when radical-right politicians are represented in parliament. Just like the majority of individuals regards underpriviliged groups in a more positive light after they are represented in institutional bodies, the views of radical-right candidates are likely to be perceived as less stigmatized once they acquire parliamentary representation. Importantly, the centrality of parliaments in 
democratic systems, and their salience in the media, means that the signal about normative change provided by parliamentary representation is highly public. In other words, each individual knows that most other members of society are also made aware of the normative signal - thus creating what Chwe (2013) has referred to as"common knowledge". This is an important point because previous empirical research has shown that information transmitted in public is more likely to bring about behavioral change than information transmitted in private (Arias; Gottlieb 2016; Gulzar and Khan 2017).

\section{Empirical Strategy}

Testing the extent to which the parliamentary presence of RRPs normalizes radical right support is complicated by the need to distinguish between two types of individuals. On the one hand, individuals who support the radical right but who abide by social norms against the expression of such ideology, and hence falsify their preferences. On the other hand, voters who simply do not support the radical right. The obvious difficulty is how to know what someone's true preferences if they are consciously concealing them. The empirical sections of this paper rely on three complimentary studies that find ways of overcoming this problem.

The first and third study take advantage of the fact that the vote share of RRPs is consistently under-reported in post-electoral surveys. As Figure 1 shows, this difference is of around 1.6 percentage points, meaning that only around $80 \%$ of the official vote for RRPs is reported in the post-electoral surveys included in CSES. As Table A1 in the Online Appendix shows, this difference is statistically significant $(p<0.001)$. Figure 1 also shows that this under-report happens only for RRPs. Parties of other ideological placements are either not underreported or, if anything, over-reported in post-electoral surveys.

The under-report of voting for RRPs is likely to happen because a survey interview is still a social interaction, and social norms can influence the answers given by respondents. 


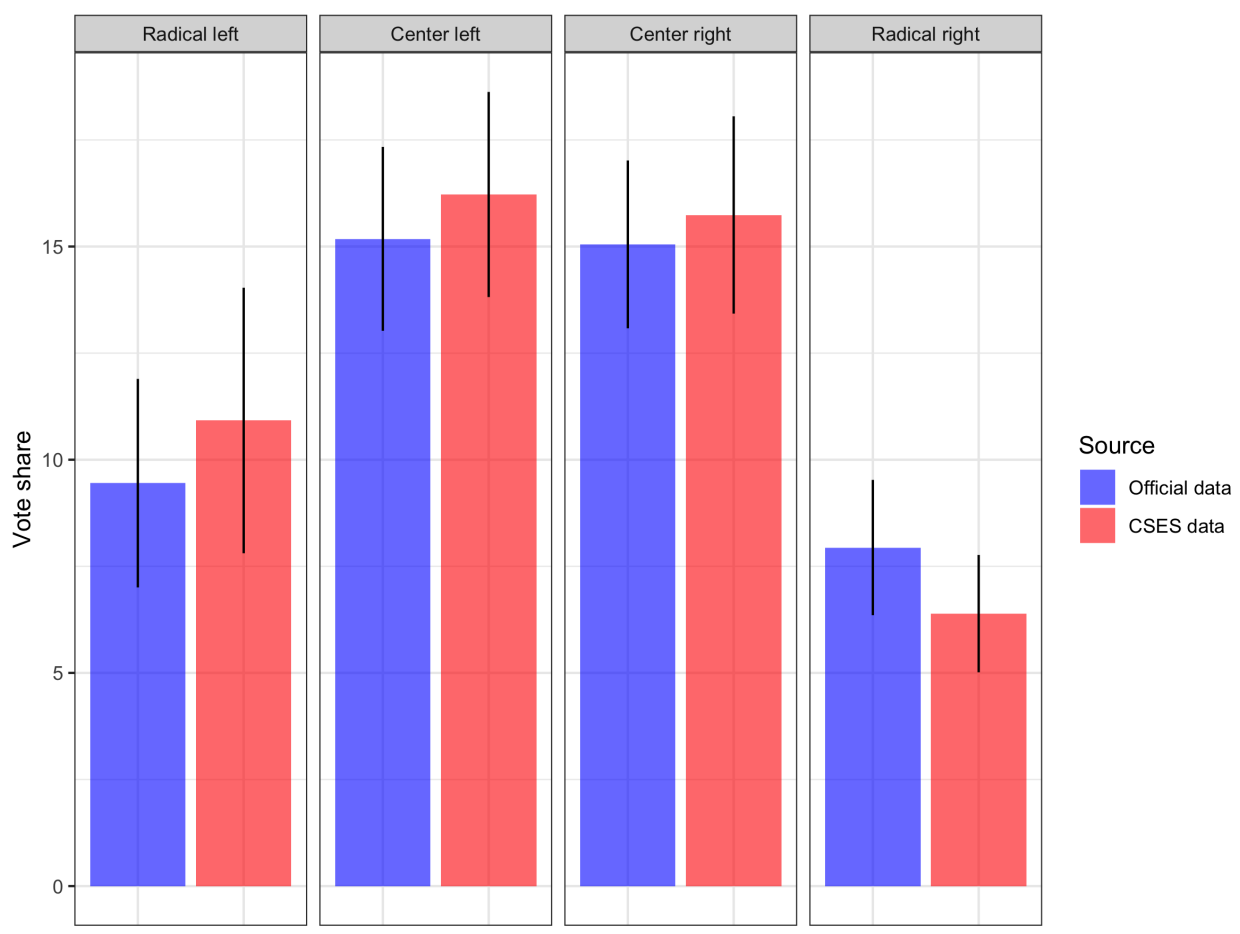

Figure 1: Difference between parties' official vote share and their vote share as reported in post-electoral surveys (CSES).

Notes: The parties included in this plot are the same ones as those included in the analyses of Study 1. Radical-left parties are coded according to the work by March (2011). Radical-right parties are coded according to the work by Norris (2005), Mudde (2007) and more recent references (see Table A5 in the Online Appendix for the full list of parties coded as radical right, as well as the references that justify that coding). Center-left parties are those whose CHES left-right placement is between 2 and 5.5 and which are not coded as radical left. Center-right parties are those whose CHES left-right placement is between 5.5 and 8 and which are not coded as radical right.

They are likely to feel judged by the interviewer and try to provide what they perceive as the socially desirable answer (Zaller 1992). While the fact that the interviewer is aware of the respondents' answer may seem like a rather weak treatment, a large body of literature has documented that others' awareness of one's actions can significantly alter behavior. For example, turnout is higher if individuals are aware that their neighbors or household members will be informed of whether they decided to vote (e.g. Gerber, Green, and Larimer 2008). Similarly, donations and public good spending increase when the donator can make others aware (Ariely, Bracha, and Meier 2009; Andreoni and Petrie 2004; Kessler 2011). When it comes to survey answers, a large body of literature has expressed concerns that the answers individuals provide in surveys conforms to social norms (Blair and Imai 2012, pp. 47). Faced with an unknown interviewer, respondents 
have an incentive to try and manage the impression they convey by providing the normabiding answer (Kuklinski, Cobb, and Gilens 1997, p. 327). For this reason, some research has provided respondents with the information that the researcher will be made aware of their actions as a ways of manipulating extrinsic motivations stemming from possible social sanctions. In so doing, these studies have found such treatment to significantly alter behavior, making respondents more likely to act in norm-compliant ways (Bursztyn, Egorov, and Fiorin 2017; Bursztyn et al. Forthcoming).

Empirical research in political science has also found that perceptions of which answer is socially desirable influence how individuals report their behavior in surveys. For example, it has been consistently found that individuals tend to over-report voter turnout (Berent, Krosnick, and Lupia 2016; Bernstein, Chadha, and Montjoy 2001; McDonald 2005). This over-report seems to be partly explained by the level of turnout in the previous election (Karp and Brockington 2005), which suggests that the higher the social pressure to vote, the higher the likelihood that voters will report having voted when in fact they did not.

One can thus take the under-report of the vote for RRPs in post-electoral surveys as measure of the perceived strength of social norms against expressions of support for the radical right. Feeling that voting for the radical right is socially sanctioned, individuals have an incentive not to report it. Hence, the proportion of individuals who report voting for the radical right can be taken as a measure of how many individuals are likely to express that preference despite the social sanctions associated with it. These social pressures, however, should be much lower - or even inexistent - in the voting booth. As voting is secret, others will not know what one has voted for and are less likely to engage in sanctioning (Ewing 2001; Kuran 1995). Consequently, the vote share for RRPs can provide a measure of how many individuals in a population privately support the radical right, and the proportion of that vote that is reported in post-electoral surveys can be used as measure of the extent to which individuals in a population perceive the expression of radical right support as acceptable. 
Taking advantage of this, Study 1 presents comparative evidence showing that individuals feel more confident in reporting having voted for an RRP when that party is in parliament. Following Dinas, Riera, and Roussias (2015), this study employs an RDD that takes advantage of exogenous variation in legally fixed electoral thresholds to parliamentary entry and compares parties just above and just below those thresholds. The dependent variable is the proportion of the official vote share for each party that is reported in post-electoral surveys. ${ }^{2}$ I rely on the CSES given the high quality of its data collection protocol and its comparability across different systems. For each country, I collected the vote share for each party in each election, as reported in CSES. Afterwards, I collected the official electoral results of the same parties in the same election. To calculate the final dependent variable (reported vote), I divided the vote share for the party in CSES by its official vote share: ${ }^{3}$

$$
\text { Reported vote }=\frac{\text { Vote share in CSES }}{\text { Official vote share }}
$$

In coding the parties as radical right, I follow two classical references on the comparative study of this party family: Mudde (2007) and Norris (2005). The coding of the parties was done such that any party considered to be radical right by at least one of these authors was coded as such. In other words, parties that were considered to be an RRP by both authors were coded as radical right; as were parties that were coded as such by one author but not by the other. Doing so avoids concerns of leaving some countries out by the sole reason they are not included in one of the references. Table A8 in the Online Appendix shows that the results remain identical after removing parties regarding which

\footnotetext{
${ }^{2}$ Previous research has already taken non-declared vote for parties as a measure of their acceptability (Fernández-Vázquez and Dinas 2012).

${ }^{3} \mathrm{~A}$ potential criticism of using this dependent variable is that people may have strategic considerations when casting a vote that are not present when they respond to a survey. Voters may strategically vote their second most preferred option and then report their first option when asked during the post-electoral survey. Should this happen, however, small parties like RRPs should be over-reported in post-electoral surveys. As shown in Table A1 in the Appendix, the exact opposite happens. RRPs are significantly under-reported in the surveys that are part of CSES.
} 
there are discrepancies between these two references. I also included some parties that became successful after those references were published, and which the literature tends to consider as radical right. ${ }^{4}$ Table A5 in the Online Appendix provides the full list of parties coded as radical right, along with the references that consider them to be so.

Study 2 complements this study by drawing upon into individual-level data. It takes advantage of variation in the interview mode of CSES respondents. Some elections in the CSES simultaneously include respondents who were interviewed in a way that forced an interaction with an interviewer, such as telephone or face to face interviews (what I call public modes of interview); and respondents who were interviewed in a way that did not force such interaction, such as internet, self-administered, or mail-back interviews (what I call private modes of interview). Because social norms are less likely to influence private behavior, I take the group of respondents interviewed in private modes as a control group. Then I regress how much respondents report to like each party on their mode of interview (private or public), a dummy for whether the party was in parliament, a dummy for whether the party is an RRPs, and the three-way interaction between these variables.

\footnotetext{
${ }^{4}$ The parties which are not included in Mudde (2007) or Norris (2005) but which were coded as radical right are the following (followed by references that categorize them as such): Dutch Party for Freedom (PVV) (Mudde 2013; Lange and Art 2011), Independent Greeks (Aslanidis and Rovira Kaltwasser 2016), Brothers of Italy (Gattinara 2017), Latvian National Alliance (Auers and Kasekamp 2013), and Serbian Dveri (Byford 2009). I also include Greek Golden Dawn and People's Party Our Slovakia (Pytlas 2015; Mareš and Stojar 2016). Although these parties have been considered to be extreme right instead of radical right (Ellinas 2013; Dinas et al. 2016; Mudde 2014; Kluknavská and Smolík 2016), this difference is not relevant for the argument put forward in this paper. Extreme right parties are social norm defiers just like RRPs and, consequently, the argument should apply to them as well. Finally, it should be noted that Alternative for Germany (AfD) was only coded as an RRP in the election of 2017. This follows the literature on the topic, among which there is consensus that AfD was not an RRP in 2013. The initial ideological position of the party was not very clear, and it seemed to be less rightist than Bavarian CSU (Arzheimer 2015). It was not until 2015 that the party went through a split and switched to the right, becoming an unequivocal RRP (Berning 2017; Cantoni, Hagemeister, and Westcott 2017). To make sure this decision is not driving the results, however, Table A16 in the Online Appendix shows that the results hold if one codes AfD as an RRP both in 2013 and 2017.
} 
Finally, Study 3 tests the argument by looking at a single party across time. I draw upon the case of UKIP, an RRP that ran for several elections before making it to parliament. This makes it possible to study the effect of parliamentary entry on its normalization, in a way that would not be possible if the party had made it to parliament in the first election it ran for. Using data from the British Electoral Study (BES), I calculate the dependent variable of the Study 1 again (reported vote), and employ a DiD design that compares UKIP to the main parties in the country (Conservative, Labor and Liberal Democrat).

\section{Study 1: Comparative Evidence}

I start with testing the argument of the paper in comparative fashion. To do so, I rely on an RDD that takes advantage of the fact that a number of electoral systems have legally fixed thresholds that determine whether a party can enter parliament. The dependent variable is reported vote, which captures the proportion of the official vote share of the party that is reported in CSES. As discussed above, a small number of post-electoral studies included in the CSES included different modes of interview, some of which do not include an interaction with the interviewer (e.g., mail back or self-administered surveys). Study 2 below takes advantage of this variation but, in this study, I use only respondents who were interviewed in modes of interview that imply an interaction with the interviewer: telephone or face-to-face.

Because different countries have different electoral thresholds, the forcing variable is not each party's vote share, but rather the difference between a party's official vote share and the fixed electoral threshold in the country. This decision follows previous research using a similar research design (Abou-Chadi and Krause 2018). The cutoff point is the electoral threshold. The analyses include all elections included in the CSES that have a proportional or mixed electoral system and a fixed electoral threshold. I use a triangular kernel, which gives more weight to parties whose electoral results are closer to the cut-off (Fan 2018). A sharp RDD would provide estimates for the parameters of interest that 
minimize the following equation:

$$
\min _{\alpha, \beta, \gamma, \delta} \sum_{i=1}^{N} 1=\left\{c-h \leq X_{i} \leq c+h\right\}\left(Y_{i}-\alpha-\beta\left(X_{i}-c\right)-\gamma T_{i}-\delta\left(X_{i}-c\right) T_{i}\right)^{2}
$$

In this equation, $c$ is the electoral threshold in each party's country; $T$ is the treatment condition (0 meaning that the party failed to enter the parliament in that election, 1 meaning that the party did enter the parliament); $X_{i}$ is the vote share of the party in the election; and $Y$ is the dependent variable, reported vote.

Some countries in the sample have mixed electoral systems, meaning that some seats are elected using majoritarian rules. Moreover, some countries with proportional electoral systems have rules that allow parties to win seats in the parliament even if their vote share is lower than the fixed threshold. For this reason, I run a fuzzy regression discontinuity. Instead of assuming that the cutoff point dictates whether or not each unit gets the treatment, as with sharp regression discontinuity, fuzzy regression discontinuity assumes that the cutoff point increases the probability that units will receive the treatment. In practical terms, this means that the forcing variable is used as an instrument of treatment status (Imbens and Lemieux 2008). $T$ is thus instrumented by $Z$-which takes the value of 0 for parties below the threshold and 1 for parties above it - and by $Z \times c$. The first stage regression is given by the following equation:

$$
T=\alpha_{1}+\beta_{1}\left(X_{i}-c\right) \gamma_{i} Z_{i}+\delta\left(X_{i}-c\right) Z_{i}+\mu_{i}
$$

Afterwards, $\hat{T}$ is used to estimate the second-stage parameters, according to the following equation:

$$
Y=\alpha_{2}+\beta_{2}\left(X_{i}-c\right)+\gamma_{2} \hat{T}_{i}+\delta_{2}\left(X_{i}-c\right) \hat{T}_{i}+v_{i}
$$

The treatment effect is given by $\gamma_{2}$. These analyses were run using the rdrobust 
package and make use of the optimal bandwidth (Calonico et al. 2017). The robust method provided by this package is robust to large bandwidths (Calonico, Cattaneo, and Titiunik 2014), and represents the main specification used in robustness checks and additional analyses. For sake of transparency, in the main analyses I report the three approaches that are reported in the output of the rdrobust package: conventional, biascorrected, and robust. As argued by Lee and Lemieux (2010), it is important to estimate RDDs using both this non-parametric approach and a parametric approach. As such, for each model I also estimate the global polynomial regression given by the following equation:

$$
Y_{i}=\alpha_{1}+\tau D_{i}+\beta_{1}(X-c)+\beta_{2}\left(X_{i}-c\right) * D_{i}+\epsilon
$$

In this equation, $\tau$ is the treatment effect, $D$ is the treatment status (coded 1 for parties in the parliament and 0 for parties outside the parliament), $X$ is the running variable (the difference between each party's vote share and the electoral threshold), and $c$ is the cutoff point (the electoral threshold). The specific number of polynomials to be used was determined by relying on the Akaike Information Criterion (AIC), as suggested by Lee and Lemieux (2010, p. 326). In all models reported in the main text, this meant using just one polynomial - only in Table A4 in the Online Appendix did the AIC lead to the use of a different number of polynomials. Tables A18 through A30 in the Online Appendix show these tests. Table A17 in the Online Appendix shows that the main results hold if one uses a different number of polynomials.

How well does this design meet the crucial assumptions for causal identification using RDDs? One of the main assumptions of these designs is the as-if-random assumption, which postulates that the assignment of units to treatment or control group, within a given bandwidth around the threshold, is as good as random. This seems like a plausible assumption in this design. Electoral thresholds vary from country to country and RRPs cannot self-select into countries with lower electoral thresholds, nor can they manipulate their vote share to be just below or just above the threshold. RDDs also require that the 
continuity assumption is met. This assumption states that "the only change, which occurs at the point of discontinuity, is the shift in the treatment status" (Cuesta and Imai 2016, p. 377). This assumption is more restrictive than the as-if-random assumption and, in this particular design, raises the concern that other changes apart from the shift in treatment status may drive the results. As discussed in more detail below, I find no evidence that the effects are being driven by jumps in other variables around the threshold.

The sample includes all elections in the CSES that took place in non-majoritarian electoral systems and for which at least one RRP ran-a total of 80 observations from 58 elections in 21 countries. Table 1 shows the list of elections included in the sample and their electoral thresholds. ${ }^{5}$ A list of all RRPs included in the analyses can be found in Table A5 in the Appendix. While this provides for a broad array of countries, many authors have argued that RRPs across Europe and other Western democracies - such as Israel, New Zealand, Canada, and Australia - have enough characteristics in common to be classified as a single party family (Mudde 2007; Norris 2005; Rydgren 2007). One of the core characteristics of such party family is its xenophobia (Rydgren 2007, p. 242). Given that such xenophobia is at the heart of why displays of support for RRPs are socially sanctioned, one should expect the stigma against such support to be broadly present across Western democracies. At the same time, because parliaments are central governing bodies in all democratic systems, and such bodies can have a crucial role in bringing about norm change (Tankard and Paluck 2016), one should expect the effect of parliamentary entry on normalizing public expressions of support for the radical right to be fairly stable across the countries included in the sample. Similarly, while the study includes a time span of around twenty years, there are no reasons to believe that the effect of parliamentary entry would change during this period. To the extent that RRPs have

\footnotetext{
${ }^{5}$ While the data has a quasi-panel structure, the identification strategy assumes that assignment into the control and treatment groups is as good as random. This means that, in expectation, one should find similar levels of serial correlation in the group of parties just below the threshold and in the group of parties just above the threshold. The Online Appendix provides analyses including country fixed effects and survey wave fixed effects, in Tables A14 and A15, respectively. The results do not change substantially.
} 
not significantly changed their ideology and continue to breach social norms, there is no reason to expect that the stigma surrounding expressions of support for them-and the effect of parliamentary entry in lowering perceptions of such stigma - would be different across the time span of the study. Figure A2 in the Online Appendix illustrates this point by showing that the dependent variable in this study (the proportion of the official vote for RRPs that is reported in post-electoral surveys) remains stable throughout the time span of the study.

\begin{tabular}{|c|c|}
\hline Elections & Electoral Threshold \\
\hline Austria 2008, 2013, 2017 & 4 \\
\hline Bulgaria 2014 & 4 \\
\hline Croatia 2007 & 5 \\
\hline Czech Republic 1996, 2002, 2006 & 5 \\
\hline Denmark 1998, 2001, 2007 & 2 \\
\hline Estonia 2011 & 5 \\
\hline Germany 1998, 2002, 2005, 2009, 2013, 2017 & 5 \\
\hline Greece 2009, 2012, 2015 (Jan), 2015 (Sep) & 3 \\
\hline Hungary 1998, 2002, 2018 & 5 \\
\hline Israel 1996, 2003 & 1.5 \\
\hline Israel 2006, 2013 & 2 \\
\hline Italy 2006 & 4 \\
\hline Italy 2018 & 3 \\
\hline Latvia 2010, 2011, 2014 & 5 \\
\hline Netherlands 1998, 2002, 2006, 2010 & 0.67 \\
\hline Norway 1997, 2001, 2005, 2009, 2013 & 4 \\
\hline Poland 1997, 2001, 2005, 2007 & 5 \\
\hline Romania 1996 & 3 \\
\hline Romania 2004 & 5 \\
\hline Serbia 2012 & 5 \\
\hline Slovakia 2010, 2016 & 5 \\
\hline Slovenia 1996 & $\approx 3$ \\
\hline Slovenia 2004, 2008 & 4 \\
\hline Sweden 2006, 2014 & 4 \\
\hline Ukraine 1998 & 4 \\
\hline
\end{tabular}

Source: Author's elaboration, based on data from the European Election Database and official data from each country.

Table 1: List of elections included in the sample and their electoral thresholds.

Figure 2 shows the results of the analyses. The left-hand side panel plots the share of the official vote for each RRP that is reported in CSES, with the electoral threshold as a cutoff point. The $\mathrm{x}$-axis represents how many percentage points above or below 
that threshold each parties was. The figure suggests that there is, indeed, a discontinuity around the threshold of parliamentary representation, such that the share of the official vote that is reported in CSES is lower for RRPs just below the threshold than for those just above it.

The panel on the right-hand side of the Figure shows the coefficients from this regression discontinuity. I estimate parametric and non-parametric models that estimate the local average treatment effect (LATE) of parliamentary entry on the normalization of RRPs. As mentioned above, I replicate the analyses using the dependent variable weighted according to the demographic weights provided by CSES. To make sure that the effect is specific to RRPs, I also run a placebo where I replicate the same analyses for center-right parties. These were coded based on the Chapel Hill Expert Survey (CHES) (Bakker et al. 2015). I considered any party to be center-right whenever it was not coded as radical right and its ideological position in the CHES was between 5.5 (center) and 8. ${ }^{6}$ The parametric models include a global bandwidth, while the non-parametric models make use of the optimal bandwidth (Calonico, Cattaneo, and Titiunik 2014).

This panel shows that the LATE is between 37 and 51 percentage points, depending on model specification. This is a remarkable effect: for each 10 individuals that voted for an RRP, four to five more were willing to tell the CSES interviewer that had done so when the party had narrowly made it to the parliament than when it had narrowly failed to do so. The results are very similar using the weighted and unweighted dependent variable, which suggests that they are not being driven by differences in the demographic characteristics of voters. Table A6 in the Online Appendix provides further evidence of this point. In turn, this effect cannot be replicated when one draws upon center right-parties. The LATEs for the analyses of these parties mostly fail to reach statistical significance

\footnotetext{
${ }^{6} \mathrm{~A}$ replication of the analyses using parties of the radical left would be a useful comparison. Unfortunately, however, there are not enough observations in the sample to run such analysis based on one of the most authoritative classifications published - that of March (2011) — or using parties with an expert placement in CHES below 2. Table A4 in the Online Appendix replicates the main analyses using only center-left parties and using all left-wing parties.
} 

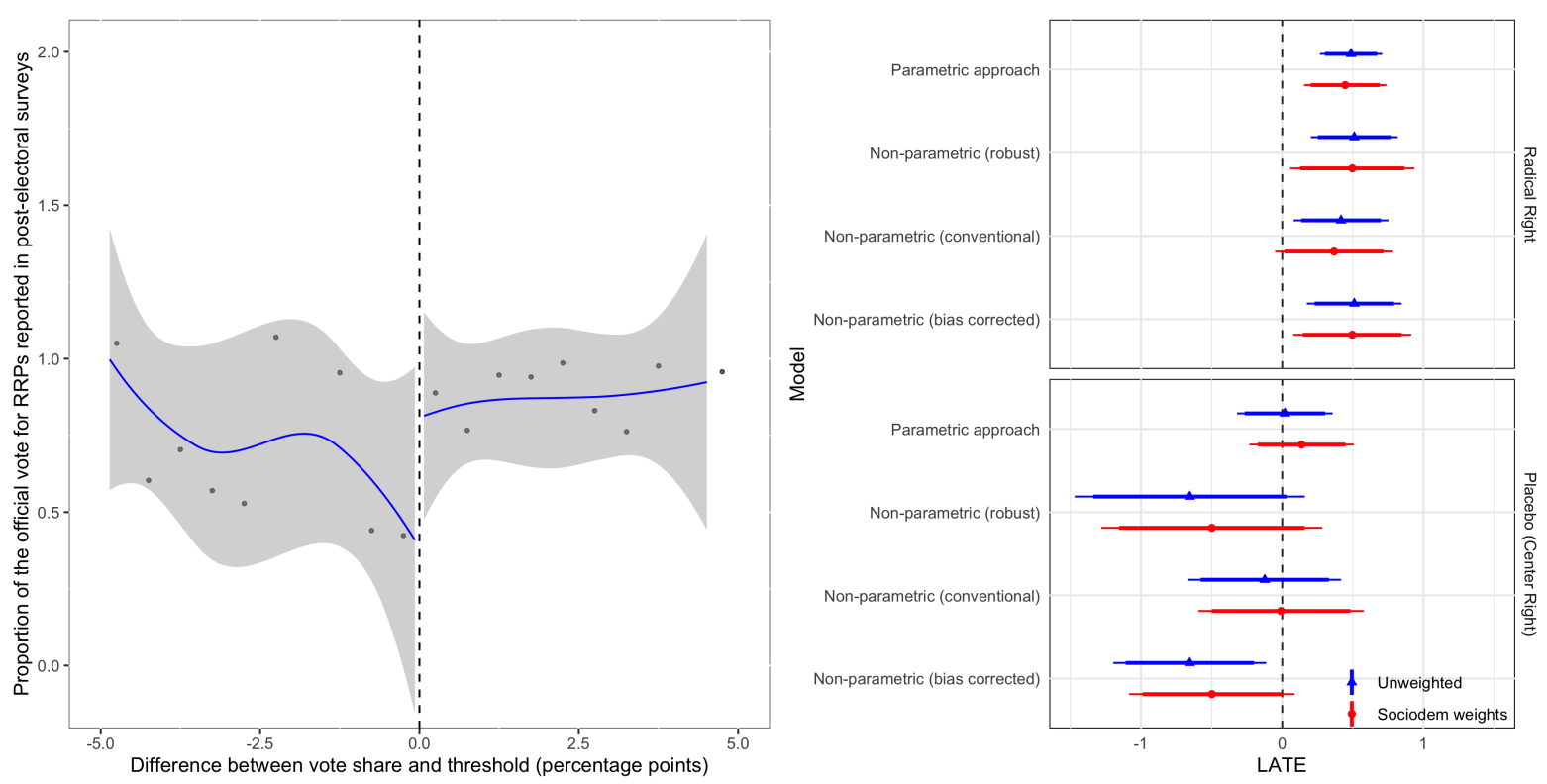

Figure 2: Effect of parliamentary representation on the normalization of the radical right support (regression discontinuity design).

Notes: In the left panel, dots represent local averages; shaded areas represent $95 \%$ Confidence Intervals. In the right panel, thick lines represent $90 \%$ confidence intervals; thin lines represent $95 \%$ confidence intervals. All non-parametric models make use of the optimal bandwidth (Calonico, Cattaneo, and Titiunik 2014); parametric models use a global bandwidth. Following the Akaike Information Criterion (AIC), the parametric models include one polynomial. Table A18 shows the AIC for these models. Tables A2 and A3 represents these analyses in Table format. In all models, standard errors are clustered by country.

and, for the most part, have negative signs. This suggests that the normalization effect of parliamentary entry is specific to the radical right. Figure A1 in the Online Appendix further shows that this is because center-right parties are not under-reported, regardless of their treatment status - which is consistent with the pattern shown in Figure 1, according to which RRPs are the only set of parties under-reported in post-electoral surveys.

This design makes the crucial assumption that the difference in the reported vote for RRPs in and out of parliament is due to a difference in the stigmatization of revealing one has voted for the radical right. Four main alternative interpretations might be advanced. In the first place, the results might be the product of a bandwagon effect, by which individuals are more likely to report voting for a successful party than for an unsuccessful one. To the extent that parliamentary representation represents a proxy for success, this might explain the findings of Figure 2. If this were the case, however, one should find an effect when replicating the same analyses using parties with different ideological 
placements. Figure 2 already showed that this effect is not replicated when drawing upon center-right parties. Table A4 in the Online Appendix provides further evidence on this point, by replicating the main analyses for center-left parties and for all parties left of center. Again, I find no evidence of a similar effect. Taken together, these analyses pay no support to the interpretation that the results can simply be explained by a bandwagon effect.

Another alternative explanation is that the results are not being driven by a normalization effect, but rather by a difference in the characteristics of individuals who are successfully contacted to answer post-electoral surveys when RRPs narrowly make it to parliament and narrowly fail to do so. Table A6 test for this possibility. It shows that there are no significant differences in the demographic characteristics of respondents successfully contacted to answer surveys when RRPs are just above and just below the threshold.

In the third place, the results might be driven by party-systems of treated parties being generally more rightists, which might make respondents more willing to report having voted for an RRP. Figure A7 shows no evidence supporting this alternative explanation, as there is no evidence of a relation between reported vote and the mean left-right mean of the remaining parties.

Finally, the results might be driven by RRPs that narrowly cross the threshold being more moderate than those that narrowly fail to make it across the threshold. To address this possibility, Table A7 replicates the main analyses shown in Figure 2 using the leftright position of RRPs as the dependent variable. I find no evidence that RRPs above the threshold are significantly less rightist than RRPs below the threshold.

This being said, these analyses present the caveat that they are unable to disentangle between two explanations. It may be that when RRPs are not in parliament, their supporters avoid telling the interviewer that they supported the party - a situation that changes once these parties make it to parliament. But the results may also be driven by voters of other parties who, once RRPs are represented in parliament, say that they voted 
for an RRP instead. It should be note, however, that both explanations are compatible with the interpretation that reporting having voted for an RRP become less stigmatized when these parties make it to parliament.

Appendix A in the Online Appendix provides a number of additional analyses related to the analyses of Study 1. In the first place, Figure A3 shows evidence that suggests that the under-report of RRPs out of parliament does not overwhelmingly happen at the expense of revealing any other kind of behavior - if anything, it happens at the expense of more individuals reporting voting for center-right parties. Figure A4 shows that the effect seems to be stronger on RRPs that were in parliament in the previous election and fail to enter parliament in the current election.

This Appendix also provides a number of robustness checks. Figure A5 plots the McCrary test for sorting. The $p$-value for the null of no-sorting is 0.90. Figure A6 shows that there is a strong first stage. Figure A8 replicates the RDD analyses using a number of different bandwidths. To make sure that the results are not being driven by influential country cases, Figure A9 replicates the analyses after removing each of the countries. Table A8 shows that the results remain similar if one removes parties that are coded as RRPs by Norris (2005), but not by Mudde (2007), and vice-versa. Table A9 shows an alternative specification of the main model. Instead of using the proportion of the official vote that is reported in post-electoral surveys as the dependent variable, these analyses take the vote share of each party in the post-electoral surveys as the dependent variable. Because some elections include more than one RRP, Table A10 replicates the main analyses using an alternative dependent variable, coded as the overall proportion of the vote for all RRPs running for a given election that is reported in post electoral surveys; Table A11 replicates the analyses including a control for the overall vote share for RRPs in each election; and Table A12 replicates the main analyses using only the most voted RRP in each election. Table A13 replicate the analyses controlling for district magnitude. Tables A14 and A15 replicate the main analyses including country fixed effects and survey wave fixed effects, respectively. Finally, Table A17 shows that the findings hold using a parametric approach with different number of polynomials. 


\section{Information shock or institutions signaling norm change? Investi- gating the mechanism}

These findings raise the question of what mechanism is driving them. In the theoretical section, I discuss two possibilities: that parliamentary representation works as an information shock about the true number of individuals who privately support the radical right; and that, in including the radical right in them, parliaments signal norms to have shifted towards a lower stigmatization of radical-right support. While not being in the position to truly test which of these mechanisms is at play, the following analyses test observable implications of each of the two mechanisms.

If the results are being driven by elections revealing the pervasiveness of radical-right support in one's society, the effect should be stronger in elections with higher thresholds. The rationale is that, where thresholds are higher, parties need a higher vote share to enter parliament, making it a stronger signal of good electoral performance. Ideally, I would like to test this expectation by replicating the analyses shown in Figure 2 on two subsamples: the subsample of elections whose threshold is higher than 4 (the median threshold in the sample); and the subsample of the remaining elections. Unfortunately, the number of observations does not allow for this subsample analyses to be carried out. For this reason, I carry out descriptive analyses that show the proportion of the official vote for RRPs that is reported in post-electoral surveys as a function of the distance to the threshold, in the two subsamples.

The results, shown in Figure 3, do not seem to pay support to the information shock mechanism. The effects seem stronger in elections with low thresholds than in elections with high thresholds. This is the opposite of what one should find according to the information shock mechanism.

I then move on to testing an observable implication of the institutional signaling mechanism. If the effect is being driven by institutional presence signaling a norm shift that makes the radical right less stigmatized, individuals should need some time 

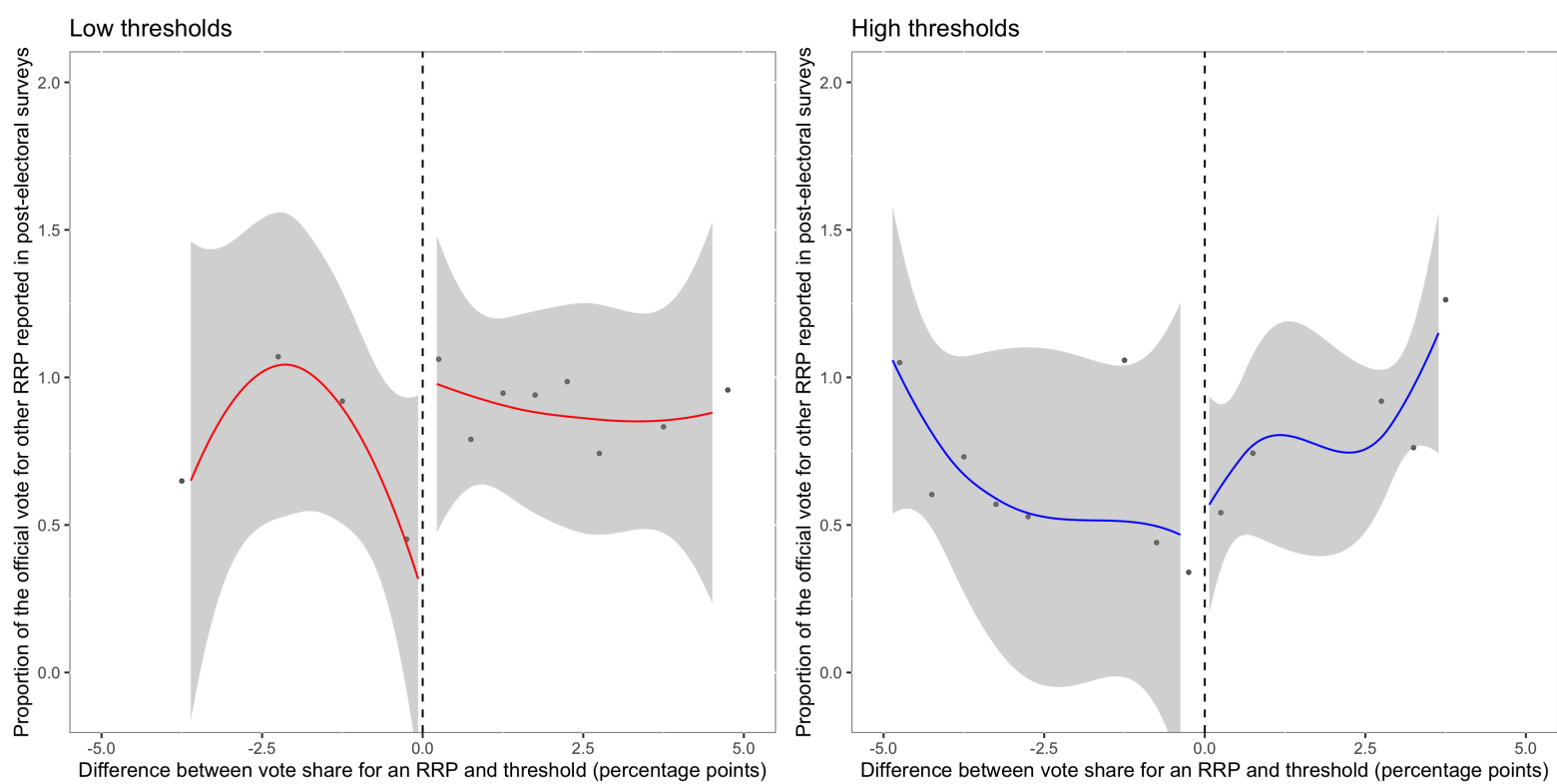

Figure 3: Proportion of the official vote for RRPs reported in post-electoral surveys as a function of the distance to the threshold, conditional on size of electoral threshold.

Note: Vertical lines represent 95\% Confidence Intervals. Dots represent local averages.

to learn about this normative change - unlike with the information shock mechanism, which should operate immediately after the election. I empirically assess this possibility by looking at how the effect changes, conditional on the distance between the date of the election and the date of the survey interview. To do so, I run linear probability models that regress a dummy coded 1 for individuals who reported having voted for an RRP and 0 for all others on a fully factorized variable indicating how many days had gone by since the election. I perform this exercise twice, once for RRPs that entered parliament and once for RRPs that did not enter parliament. To decrease concerns that the results may be driven by differences in the sociodemographic characteristics of individuals interviewed at different stages of the fieldwork period, the analyses make use of the demographic weights provided by CSES. The models also include election fixed effects.

As the results in Figure 4 show, the data seem to support this mechanism. This Figure plots the predicted probability of reporting having voted for an RRP as a function of the distance between election day and interview day. While the probability of reporting having voted for an RRP out of the parliament is stable over time, the probability of reporting having voted for an RRP that entered parliament increases. This is what 
one would expect following the institutional signaling mechanism, but not following the information shock mechanism.

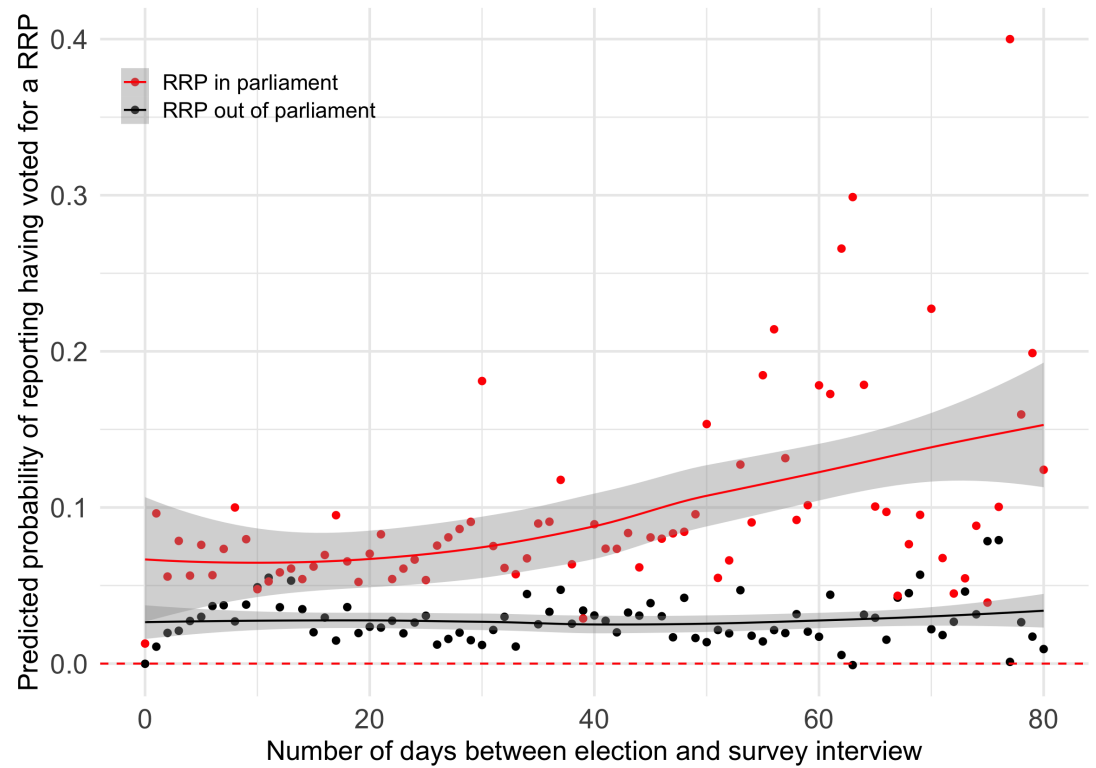

Figure 4: Predicted probability of reporting having voted for a radical right party as a function of the distance between the date of the election and the date of the survey interview.

Note: Shaded areas represent 95\% Confidence Intervals. The models include election fixed effects. Standard errors are clustered by election.

\section{Study 2: Individual-Level Evidence}

Study 1 relies on a measures of social norms at the party level. Study 2 provides a complement to it by drawing upon individual-level data. It takes advantage of the fact that, in some elections included in the CSES, different respondents were interviewed using different modes of interview. While interviews over the telephone or face-to-face made the answers of respondents public - in that they included an interaction with the interviewer-, mail-back, online, and self-administered surveys kept answers private. ${ }^{7}$

\footnotetext{
${ }^{7}$ To be sure, there is some variation in the level of "publicness" within these modes of interview. Interviews performed face-to-face are likely to be more affected by social norms than are interviews over the telephone. Unfortunately, the within-country variation in modes of interview is not enough to allow for more fine-grained comparisons. The countries included in these analyses include only two different
} 
The difference in interview mode is important because social norms should interfere less with private behavior such as survey answers using private modes of interview. The two remaining studies draw exclusively upon answers to surveys whose interviews were conducted in public modes. By contrast, this study takes advantage of variation in the interview modes and uses the group of respondents interviewed in private modes as a control group, who are more likely to report their true preferences.

I draw upon data from all elections in the CSES that include more than one mode of interview: Greece 2012 (June) and 2015 (January and September); Italy 2018; and Denmark 2007. I also included Germany 2002, which has two full studies in Round 2 of the CSES: one fully employing telephone interviews, and another fully employing mailback surveys. As a dependent variable, I use the item asking how much each respondent reports to like each party, in a scale from 0 to 10 . The main independent variables are a dummy for the mode of interview (coded 1 for private modes and 0 for public modes), a dummy for RRPs, and a dummy for whether each party had made it to parliament in the election previous to the survey. I also include an interaction term between these three variables, which is what I am substantively interested in. The extent to which respondent $i$ reports liking party $j$ is thus given by the following equation:

$$
\begin{aligned}
\text { Like }_{i j}=\alpha & +\beta_{1} \text { Public }_{i}+\beta_{2} \text { Radical Right }_{j}+\beta_{3} \text { Parliament }_{j} \\
& +\beta_{4} \text { Public }_{i} \times \text { Radical Right }_{j}+\beta_{5} \text { Parliament }_{j} \times \text { Radical Right }_{j} \\
& +\beta_{6} \text { Parliament }_{j} \times \text { Private }_{i}+\beta_{7} \text { Public }_{i} \times \text { Parliament }_{j} \times \text { Radical Right }_{j}+\epsilon
\end{aligned}
$$

Each individual was included in the sample several times: one for each party for modes of interview. Hence, one is unable compare how individuals report to like parties across different modes of interviews coded as public. This being said, the comparison between private and public modes should be the crucial one for the argument put forward here, as it captures whether individuals have to report their answer to an interviewer or not. 
which there is data concerning the dependent variable. To account for this, standard errors are clustered by individual. ${ }^{8}$ The results are shown in Figure 5.

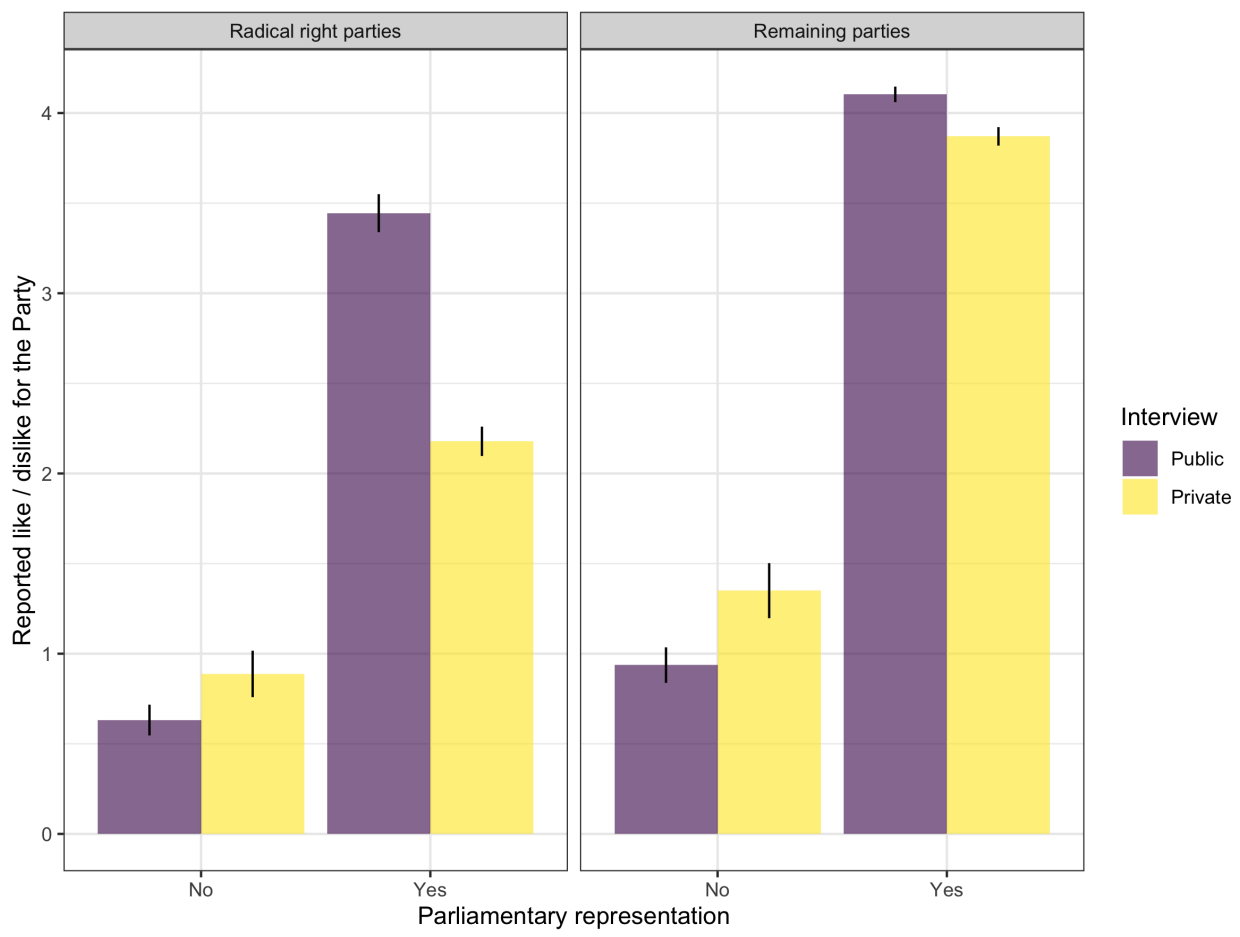

Figure 5: Reported like / dislike for radical right and remaining parties, in and out of the parliament, by mode of interview.

Note: Vertical bars represent $95 \%$ confidence intervals.

As the Figure shows, all variables have the expected effect. Individuals tend to like RRPs less than the remaining parties; to like parties which are in parliament more; and to report liking parties more when the mode of interview is private. The difference between how much individuals reporting liking a party in private and public modes of interview is reduced when the party makes it to the parliament, but this reduction is larger in the case of RRPs. The coefficient of this three-way interaction is 0.876 . This represents around $25 \%$ of the mean dependent variable in the whole sample (3.52), making the coefficient of the three-way interaction far from negligible in substantive terms.

While all the variables all have the expected direction, the large magnitude of the

\footnotetext{
${ }^{8}$ Ideally, the model would include individual-level fixed effects. However, that is not possible because that would remove any variation mode in the modes of interview: a respondent was either interviewed in a private mode or in a public mode.
} 
three-way interaction leads to the unexpected result that, when RRPs are in the parliament, individuals report liking them more in public modes of interview than in private ones. A possible interpretation of this finding is that the parliamentary entry of an RRP leads its supporters to feel some sense of euphoria that makes them extract utility from publicly expressing support for the party. Because the dependent variable in this study is a continuous variable that allows individuals to express the extent of their liking for a party — as opposed to just reporting having voted for it or not, as in Study 1-, the feeling that the parliamentary entry of the party has legitimized its views can make individuals more eager to signal their support for the RRP, giving it a higher score. Since the utility extracted from such signaling is likely to affect public modes of interview more strongly than private ones, this could be driving the unexpected value.

The crucial assumption in this design is that individuals interviewed using private and public modes of interview are comparable, which may not necessarily be the case. To the extent that individuals may not be randomly assigned into different modes of interviews, the same characteristics that affect their assignment into a specific mode of interview can also affect the answers they provide. Table B1 in Appendix B in the Online Appendix addresses this concerns with two different strategies: by adding a number of control variables; and by estimating models that make use of the demographic weights provided by CSES. The models including control variables also control for the vote share of each party, which could be confounding the relation between parliamentary presence and the outcome variable. This table also replicates the analyses comparing RRPs only to center-right parties, instead of comparing them to all other parties. The results of these models are substantively similar to the ones presented in Figure 5. Finally, this Appendix provides some further detail to the analyses of this study. Figure B1 shows that the effect of parliamentary entry on normalizing public expressions of support for the radical right is larger for individuals with a college degree.

One question that is raised by the findings shown in Figure 5 is which individuals become more likely to report liking an RRP when the party is in parliament. In this study I have data on the party each individual voted for, which allows me to provide further 
detail on this question. To do so, I focus on how individuals rate RRPs alone, excluding all other parties. Afterwards, I check how much individuals report liking RRPs in and out of parliament, conditional on their mode of interview and the ideological position of the party they had voted for in that election. ${ }^{9}$

As shown on Figure 6, the results are much stronger for individuals who voted for right-wing parties. However, I find no evidence of a backlash effect on voters of left-wing parties. The effect remains for left-wing voters, albeit much smaller. The fact that the effect is stronger for right-wing voters is in line with previous research in psychology, which has found that the effect of norm change tends to be stronger on individuals whose private preferences were already aligned with the new norm (Tankard and Paluck 2016, pp. 198-199).

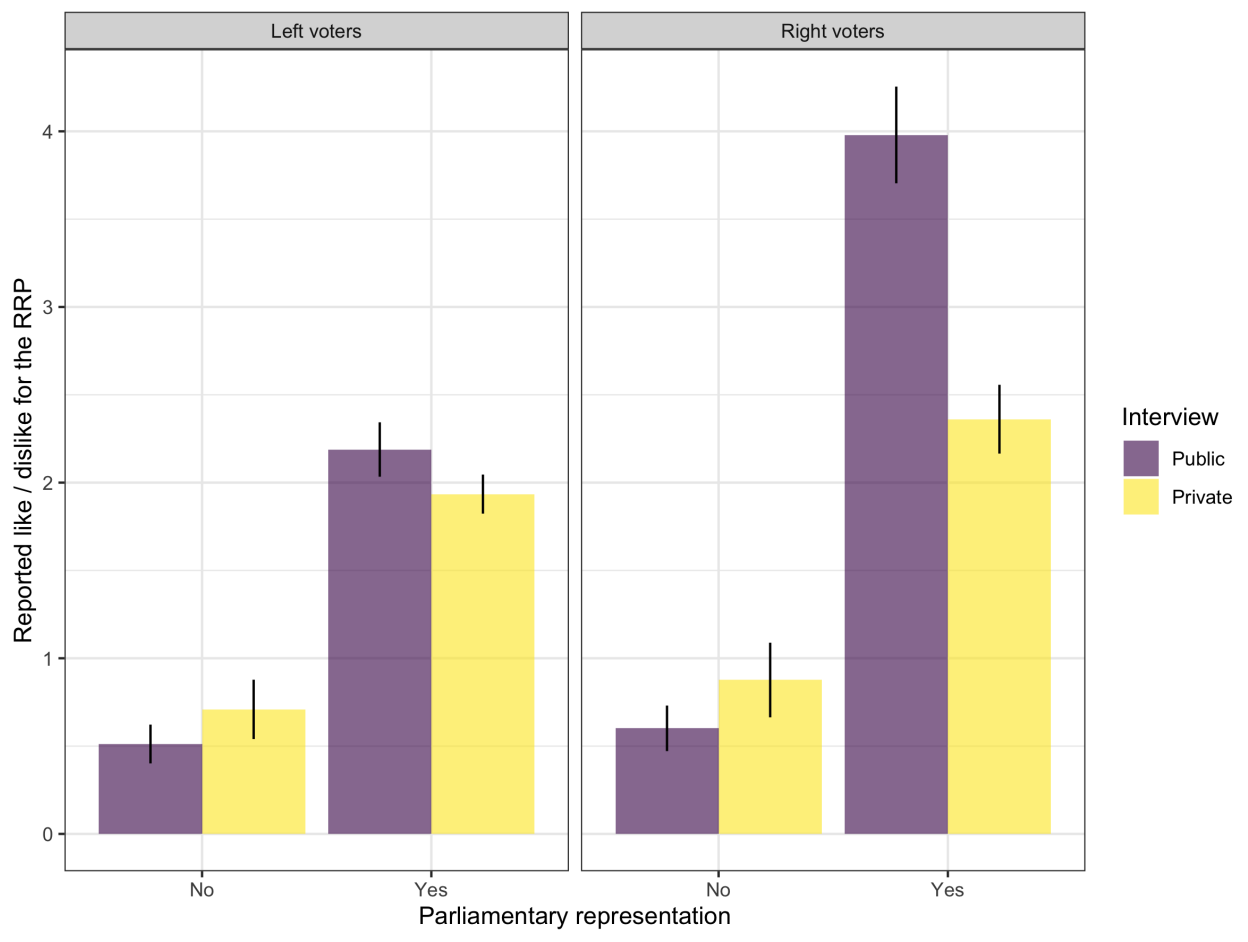

Figure 6: Reported like / dislike for radical right parties, in and out of the parliament, by mode of interview and ideology of the voter.

Note: Vertical bars represent $95 \%$ confidence intervals.

\footnotetext{
${ }^{9}$ Parties were coded according to the expert placement, as provided by CSES. Parties with a score of 5 or below (on a scale from 0 to 10) were coded as left-wing parties; parties with a score above 5 not already coded as RRPs were coded as right-wing parties.
} 


\section{Study 3: Case Study of UKIP}

The two previous studies have showed the effect of parliamentary entry on the normalization of public expressions of support for RRPs by relying on party-level and individuallevel data. These studies face the potential criticism that both compare different parties, and that they both focus on countries with proportional systems. Study 3 is designed to check if the results hold while analyzing the same party before and after it made it to parliament, and if they can be replicated in a majoritarian system. I look into the case of UKIP in the United Kingdom because it is a rare case of an RRP that ran for several elections before entering parliament, which allows one to look at differences before and after its parliamentary entry.

UKIP ran for the first time for the general election of 1997, failing to win any seat in the parliament and scoring a low $0.3 \%$ of the vote. The party remained extraparliamentary until 2015, when its norm-defying, anti-immigration rhetoric proved successful. Its campaign relied heavily on the charisma of its leader Nigel Farage, who presented himself as someone not afraid to 'tell it like it is' (Cowley and Kavanagh 2016, pp. 175-176). UKIP gained $12.7 \%$ of the vote and entered the lower house for the first time. ${ }^{10}$

To test the extent to which the parliamentary entry of UKIP normalized expressions of support to it, I draw on data from the BES and calculate the same dependent variable as in Study 1 -reported vote, which captures the share of the official vote for UKIP that is reported in post-electoral surveys. The effect of UKIP's parliamentary entry on this variable was estimated using DiD models, which calculate the average treatment effect on

\footnotetext{
${ }^{10}$ It should be noted that the one MP elected by UKIP in this election, Douglas Carswell, was a previous Conservative MP. It could be argued that this would not provide such a clear signal to voters that a norm-breaking party had entered the parliament. However, the leader of the UKIP Campaign was still Nigel Farage and the campaign was dominated by a number of norm-breaking claims. The party brand should be more important than who specifically won the seat. Moreover, if anything, this fact should make the estimates more conservative by lowering the intensity of the signal provided by the parliamentary entry of UKIP and making it harder to find an effect.
} 
the treated (ATT) by comparing the difference between post- and pre-treatment values of treated units to those of units that do not receive the treatment. Assuming that, in the absence of the treatment, the two sets of units would follow parallel trends, the control group provides the missing potential outcome: the reported vote for UKIP, had it not made it to national parliament in the election of 2015.

To estimate these models, I create a binary treatment indicator coded 1 for RRPs that had made it to the parliament in the previous election, and zero otherwise. The analyses draw upon the elections of 2005, 2010 and 2015. The reported vote for UKIP is compared to that of the three main parties in the UK: Conservative, Labor, and Liberal Democrats. The ATT is then calculated on the basis of a fixed-effects model, given by the following equation:

$$
Y_{i t}=\alpha+\gamma_{i}+\lambda_{t}+\tau D_{i t}+u_{i t}
$$

In this equation, $Y_{i t}$ is the dependent variable, reported vote, for party $i$ at time $t$; $\gamma_{i}$ is a party-level fixed effect that controls for time-invariant unobserved heterogeneity; $\lambda_{t}$ is a period fixed effect that controls for similar trends; and $\tau$ is the ATT.

Figure 7 shows the results. The left-hand side panel plots the evolution of the dependent variable in the control and treatment group. As the figure shows, units in the treated and control groups followed similar trends before the election of 2015. However, in that election, the share of the official vote for UKIP that was reported in BES increased substantially. The right-hand side panel shows the results of a number of DiD estimates for the effect of parliamentary entry of UKIP on the normalization of expressions of support for it. The first model represents the DiD estimate using period fixed effects for each of the three periods included in the analyses, while the second model simply compares the pre-treatment and post-treatment periods. The third model replicates the first model, with the difference that the dependent variable makes use of the demographic weights provided by the BES. As with the previous studies, this was done to tap concerns that the results may be driven by differences in the demographic characteristics of individuals who 
reported having voted for UKIP before and after the treatment. Finally, the last model represents a placebo test that assumes the previous time point $(t-1)$ as the moment of the administration of the treatment. In so doing, it also tests for the extent to which trends in the control and treatment groups were parallel before the treatment. Should that be the case, one should find no effect when running this placebo.
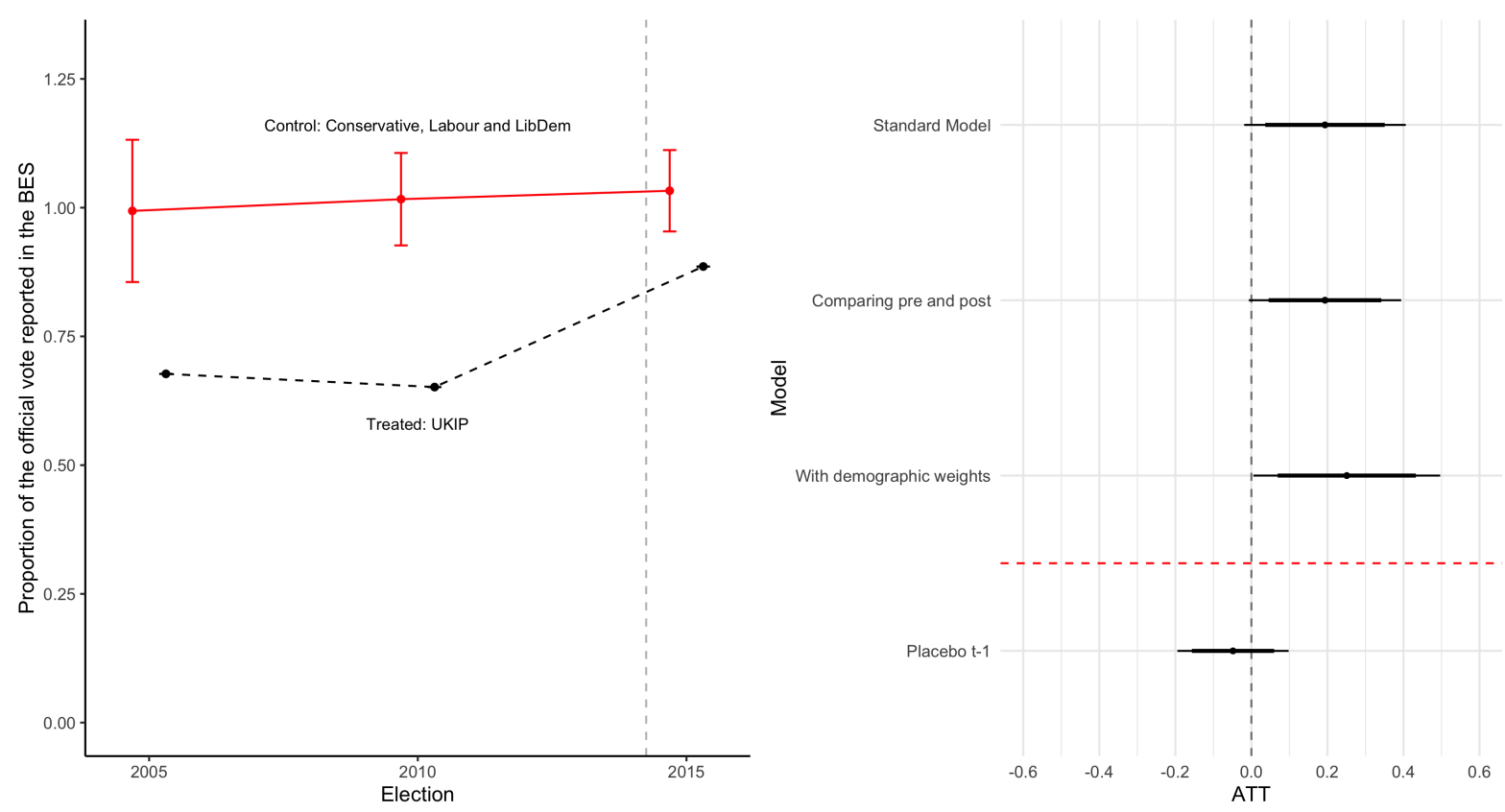

Figure 7: Effect of the parliamentary entry of UKIP on its normalization (Difference-indifferences models).

Note: Thin represent $95 \%$ confidence intervals; thick bars represent $90 \%$ confidence intervals. Standard errors are clustered by party.

Regardless of the model specification, the results show an increase in the vote share for the party that was reported in the BES in 2015. The effect size is around 20 percentage points. This means that, for each 10 people who voted for UKIP, two more were willing to tell the BES interviewer that they did so after the party made it to the parliament. This is a sizeable effect, even if smaller than the one found in the RDD in Study 1. The fact that the effect is slightly smaller than the one found in the RDD analysis of Study 1 seems to be driven by the vote for UKIP before it entered parliament being less underreported in post-electoral surveys (around 0.75 of its official vote) than that of RRPs that narrowly fail to make it to parliament in Study 1 (around 0.5 of their official vote). This suggests that UKIP was less stigmatized than the average RRP in other countries, leaving less 
room for its parliamentary entry to have a normalizing effect. Finally, it should be noted that the fourth model shown in Figure 7, using $t-1$ as the moment of administration of the treatment, finds no effect. This means that there is no evidence of a violation of the parallel trends assumption.

Appendix $\mathrm{C}$ in the Online Appendix presents some robustness check for these analyses. To check whether the results are sensitive to changes in the control group, Figure $\mathrm{C} 2$ plots the effect sizes for models using all possible combinations of the three main parties in the control group. Their mean and median are very similar to the effect sizes reported in Figure 7. Figure C3 shows the parallel trends plots comparing UKIP to each of the control parties individually: LibDem, Conservatives, and Labour. As with previous studies, a possible concern is that differences in the demographic characteristics of voters of UKIP in 2010 and 2015 may be driving the results. The fact that the results hold when the dependent variable is calculated using the demographic weights provided by BES lowers concerns that this might be the case. Figure $\mathrm{C} 1$ tests for this alternative explanation more directly, showing no evidence of differences in the sociodemographic characteristics of voters between these two periods.

One possible criticism of this study is that, in 2015, UKIP not only made it to parliament, but its vote share grew substantially. This means that, unlike with the analyses of Study 1, one cannot identify the effect of parliamentary entry alone. This raises concerns of compound treatment effect, making it unclear whether the normalization effect is being driven by the UKIP's parliamentary entry or its high vote share.

While not in position to fully dismiss this alternative mechanism, in the following I provide some analyses that are more compatible with the parliamentary entry mechanism than with the increasing vote share mechanism. If the effect is being driven by the electoral success of UKIP, and not by its parliamentary entry, one should find a similar effect when replicating the analyses drawing upon elections for the European Parliament (EP). In the EP election of 2014, UKIP was the most voted party. Thus, if the effects shown in Figure 7 are due to the good electoral result of UKIP, instead of its parliamentary 
entry, one should expect that the 2014 EP election would have had a similar effect. I check whether this is the case by replicating the analyses shown in Figure 7 drawing upon EP elections instead of national elections, using data from the European Election Study (EES). The difference is that the treatment in these new analyses is not UKIP entering the UK parliament, but rather winning the EP election of 2014.

The results are shown in Figure 8. The Figure shows no evidence of an effect similar to the one found for the analyses of national elections. There is no significant difference in the proportion of the official vote for UKIP that is reported is post-electoral surveys that follow the EP election won by UKIP as compared to previous ones. This evidence is more compatible with an interpretation that ascribes the effect shown in Figure 7 to the parliamentary entry of UKIP than to the increase in its vote share.
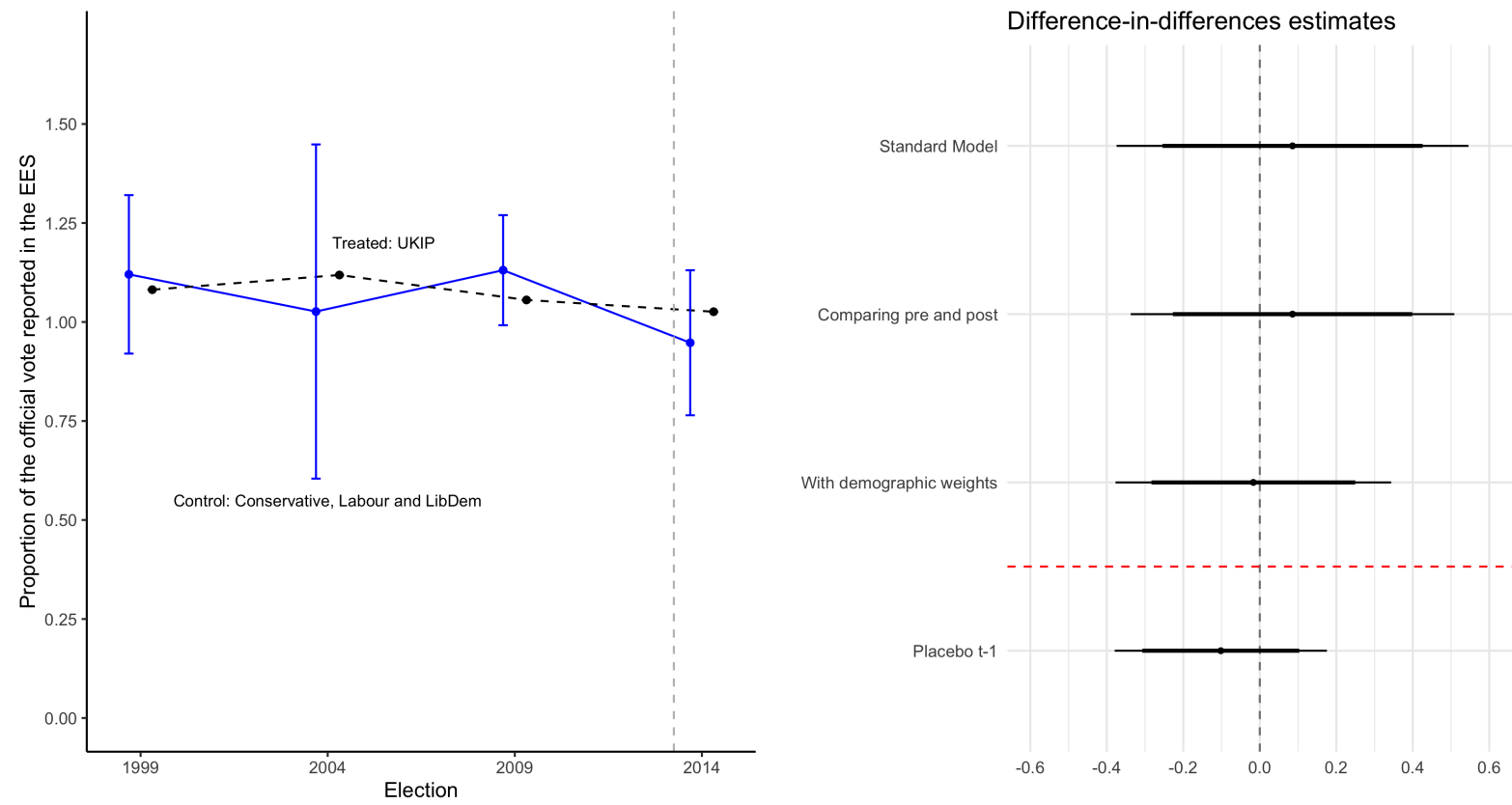

Figure 8: Replication of the analyses in Figure 7 using data from elections for the European Parliament.

Note: Thin represent $95 \%$ confidence intervals; thick bars represent $90 \%$ confidence intervals. Standard errors are clustered by party. 


\section{Conclusion}

Once created, cultural equilibria significantly affect the preferences individuals are willing to display in public. In feeling that some preferences are likely to be punished by others, individuals have an incentive to falsify them. This paper has explored a causal mechanism by which stigmatized preferences can become normalized: the parliamentary representation of radical right actors. With resource to three different, complimentary studies, I have documented how such representation can make individuals more willing to express support for the radical right. Using comparative evidence, Study 1 showed that the vote share for RRPs is significantly less under-reported if these parties are represented in parliament. Study 2 looked into individual-level data, by comparing how much voters report liking RRPs in and out of parliament depending on their interview mode. Finally, Study 3 tested the argument drawing upon a single party throughout time, and in country with a majoritarian (instead of proportional) system. The three studies employ different methods, variables and case selections, but they come to the same conclusion: the parliamentary entry of an RRP makes individuals more confident in expressing support for the radical right.

These findings make two main contributions for existing literature. In the first place, they show how the presence of norm-breaching political actors in democratic institutions can bring about processes of norm change. Previous research has shown that institutional decisions can change individual perceptions as to which behaviors are deemed acceptable in a society (Tankard and Paluck 2016). The findings of this paper highlight that not only the decisions that institutions take, but also the actors represented in them, can bring about such normative change.

This result yields an interesting paradox: the institutional presence of norm-breaching political actors can normalize those actors, even though they are often critical of those very institutions. This finding is particularly interesting considering that there is generalized pattern of decreasing trust in institutions (Catterberg and Moreno 2006), and that radical-right voters are among the most distrustful of political institutions (Zhirkov 2014). 
A possible interpretation of this seeming paradox is that, while radical-right voters have low trust in political institutions, they still take the presence in these institutions as a cue of what is accepted by others - i.e., the individuals who are likely to sanction their views. If the parliamentary presence of an RRP makes the potential sanctioners perceive that the party has been normalized, radical-right voters become less likely to be sanctioned for expressing their support. This can explain why parliamentary representation affects their willingness to express radical-right support regardless of their own views of political institutions.

The findings also highlight the role of social norms in the extent to which individuals are willing to publicly express political preferences that they hold in private. In the case of socially sanctioned preferences such as support for norm-defying politicians, individuals are likely to collect cues from their social and political environment before deciding whether to publicly express their private preferences.

The results of the paper open avenues for future research. In the first place, subsequent studies might try to gauge whether this normalization extends beyond the answers that individuals provide to survey answers - for example, in their willingness to participate in far-right demonstrations or rallies. Another potential avenue for future research is the long-term effect of this normalization process. Does the institutional presence of radical-right politicians bring about a new, stable cultural equilibrium, or is this effect limited to the short-term? While going beyond the scope of this study, these question would provide important insights into the way in which political events can affect culture. 


\section{References}

Abou-Chadi, Tarik. 2016. "Niche party success and mainstream party policy shifts-how green and radical right parties differ in their impact". British Journal of Political Science 46 (2): 417-436.

Abou-Chadi, Tarik, and Werner Krause. 2018. "The Causal Effect of Radical Right Success on Mainstream Parties' Policy Positions: A Regression Discontinuity Approach". British Journal of Political Science: 1-19. Visited on 06/19/2018. https://doi .org/ 10.1017/S0007123418000029.

Andreoni, James, and Ragan Petrie. 2004. "Public goods experiments without confidentiality: a glimpse into fund-raising". Journal of public Economics 88 (7-8): 1605-1623.

Arias, Eric. "How does media influence social norms? Experimental evidence on the role of common knowledge". Political Science Research and Methods 7 (3).

Ariely, Dan, Anat Bracha, and Stephan Meier. 2009. "Doing good or doing well? Image motivation and monetary incentives in behaving prosocially". American Economic Review 99 (1): 544-55.

Arzheimer, Kai. 2015. "The AfD: Finally a successful right-wing populist eurosceptic party for germany?" West European Politics 38 (3): 535-556.

Aslanidis, Paris, and Cristóbal Rovira Kaltwasser. 2016. "Dealing with populists in government: the SYRIZA- ANEL coalition in Greece". Democratization 23 (6): 10771091.

Auers, Daunis, and Andres Kasekamp. 2013. "Comparing radical-right populism in Estonia and Latvia". In Right-Wing Populism in Europe: Politics and Discourse, ed. by Wodak, Ruth, KhosraviNik, Majid, and Mral, Brigitte, 235-248. London: Bloomsbury.

Bakker, Ryan, et al. 2015. "Measuring party positions in Europe: The Chapel Hill expert survey trend file, 1999-2010". Party Politics 21 (1): 143-152.

Bale, Tim. 2003. "Cinderella and her ugly sisters: the mainstream and extreme right in Europe's bipolarising party systems". West European Politics 26 (3): 67-90.

Bale, Tim, Christoffer Green-Pedersen, AndréA Krouwel, Kurt Richard Luther, and Nick Sitter. 2010. "If you can't beat them, join them? Explaining social democratic responses to the challenge from the populist radical right in Western Europe". Political studies 58 (3): 410-426.

Beaman, Lori, Raghabendra Chattopadhyay, Esther Duflo, Rohini Pande, and Petia Topalova. 2009. "Powerful women: does exposure reduce bias?" Publisher: MIT Press, The Quarterly journal of economics 124 (4): 1497-1540.

Berent, Matthew K., Jon A. Krosnick, and Arthur Lupia. 2016. "Measuring Voter Registration and Turnout in SurveysDo Official Government Records Yield More Accurate Assessments?" Public Opinion Quarterly 80 (3): 597-621. Visited on 03/17/2018.

Berning, Carl C. 2017. "Alternative für Deutschland (AfD) - Germany's New Radical Right-wing Populist Party". Visited on 06/03/2019. https : / /www . econstor . eu / bitstream/10419/181255/1/dice-report-2017-4-50000000000855.pdf.

Bernstein, Robert, Anita Chadha, and Robert Montjoy. 2001. "Overreporting voting: Why it happens and why it matters". Public Opinion Quarterly 65 (1): 22-44. 
Bicchieri, Cristina. 2017. Norms in the Wild: How to Diagnose, Measure, and Change Social Norms. Oxford: Oxford University Press.

Bicchieri, Cristina, and Hugo Mercier. 2014. "Norms and beliefs: How change occurs". In The complexity of social norms, 37-54. Springer.

Bicchieri, Cristina, and Erte Xiao. 2009. "Do the right thing: but only if others do so". Journal of Behavioral Decision Making 22 (2): 191-208.

Billig, Michael. 1991. Ideology and Opinions: Studies in Rhetorical Psychology. London: SAGE.

Billig, Michael, Susan Condor, Derek Edwards, Mike Gane, David Middleton, and Alan Radley. 1988. Ideological dilemmas: A social psychology of everyday thinking. London: SAGE.

Bischof, Daniel, and Markus Wagner. 2019. "Do Voters Polarize When Radical Parties Enter Parliament?" American Journal of Political Science 63 (4): 888-904. Visited on 11/08/2019. https://onlinelibrary.wiley.com/doi/abs/10.1111/ajps. 12449.

Blair, Graeme, and Kosuke Imai. 2012. "Statistical analysis of list experiments". Political Analysis 20 (1): 47-77.

Bursztyn, Leonardo, Georgy Egorov, and Stefano Fiorin. 2017. From extreme to mainstream: How social norms unravel. Tech. rep. National Bureau of Economic Research. https://www . nber.org/papers/w23415.

Bursztyn, Leonardo, Michael Callen, Bruno Ferman, Saad Gulzar, Ali Hasanain, and Noam Yuchtman. Forthcoming. "Identifying Ideology: Experimental Evidence on AntiAmericanism in Pakistan". Journal of the European Economic Association.

Byford, John. 2009. Denial and Repression of Anti-Semitism. Budapest: Central European University Press.

Calonico, Sebastian, Matias D Cattaneo, and Rocio Titiunik. 2014. "Robust Data-Driven Inference in the Regression-Discontinuity Design". Stata Journal 10 (2): 1-36.

Calonico, Sebastian, Matias D. Cattaneo, Max H. Farrell, and Rocio Titiunik. 2017. "rdrobust: Software for regression discontinuity designs". Stata Journal 17 (2): 372404.

Cantoni, Davide, Felix Hagemeister, and Mark Westcott. 2017. "Persistence and Activation of Right-Wing Political Ideology". Volkswirtschaftliche Fakultät Ludwig-MaximiliansUniversität München.

Carmines, Edward G., and James A. Stimson. 1989. Issue Evolution: Race and the Transformation of American Politics. Princeton, NJ: Princeton University Press.

Catterberg, Gabriela, and Alejandro Moreno. 2006. "The Individual Bases of Political Trust: Trends in New and Established Democracies". International Journal of Public Opinion Research 18 (1): 31-48. Visited on 07/18/2019. https : / academic . oup . com/ijpor/article/18/1/31/797103.

Chauchard, Simon. 2014. "Can descriptive representation change beliefs about a stigmatized group? Evidence from rural India". Publisher: JSTOR, American Political Science Review 108 (2): 403-422.

Chwe, Michael Suk-Young. 2013. Rational ritual: Culture, coordination, and common knowledge. Princeton University Press. 
Coppedge, Michael, et al. 2017. V-Dem Country-Year/Country-Date Dataset v\%.1. Varieties of Democracy (V-Dem) Project. https://www.v-dem.net/en/data/dataversion-7-1/.

Cowley, P., and D. Kavanagh. 2016. The British General Election of 2015. Berlin: Springer.

Cuesta, Brandon De la, and Kosuke Imai. 2016. "Misunderstandings about the regression discontinuity design in the study of close elections". Annual Review of Political Science 19:375-396.

De Vries, Catherine E., and Erica E. Edwards. 2009. "Taking Europe To Its Extremes: Extremist Parties and Public Euroscepticism". Party Politics 15 (1): 5-28.

De Vries, Catherine E., and Sara B. Hobolt. 2012. "When dimensions collide: The electoral success of issue entrepreneurs". European Union Politics 13 (2): 246-268.

Dinas, Elias, Pedro Riera, and Nasos Roussias. 2015. "Staying in the first league: Parliamentary representation and the electoral success of small parties". Political Science Research and Methods 3 (2): 187-204.

Dinas, Elias, Vassiliki Georgiadou, Iannis Konstantinidis, and Lamprini Rori. 2016. "From dusk to dawn: Local party organization and party success of right-wing extremism". Party Politics 22 (1): 80-92.

Duverger, Maurice. 1954. Political parties: Their organisation and activity in the modern state. Google-Books-ID: rhGHAAAAMAAJ. London: Methuen; Wiley.

Ellinas, Antonis A. 2013. "The rise of Golden Dawn: The new face of the far right in Greece". South European Society and Politics 18 (4): 543-565.

Ewing, Gordon. 2001. "Altruistic, egoistic, and normative effects on curbside recycling". Environment and Behavior 33 (6): 733-764.

Fan, Jianqing. 2018. Local polynomial modelling and its applications: monographs on statistics and applied probability 66. London: Routledge.

Fernández-Vázquez, Pablo, and Elias Dinas. 2012. "Projection Bias in the Survey Placement of Spanish Political Parties: Differences between National and Regional Parties". South European Society and Politics 17 (3): 519-531.

Gattinara, Pietro Castelli. 2017. "Framing Exclusion in the Public Sphere: Far-Right Mobilisation and the Debate on Charlie Hebdo in Italy". South European Society and Politics 22 (3): 345-364. Visited on 07/24/2019. https://doi.org/10.1080/ 13608746.2017 .1374323$.

Gerber, Alan S., Donald P. Green, and Christopher W. Larimer. 2008. "Social pressure and voter turnout: Evidence from a large-scale field experiment". American Political Science Review 102 (1): 33-48.

Gerber, Alan S., and Todd Rogers. 2009. "Descriptive Social Norms and Motivation to Vote: Everybody's Voting and so Should You". The Journal of Politics 71 (1): 178191.

Global Health Observatory. 2018. WHO / Global Health Observatory (GHO) data. Visited on 10/23/2018. http://www. who.int/gho/en/.

Goldstein, Noah J., Robert B. Cialdini, and Vladas Griskevicius. 2008. "A Room with a Viewpoint: Using Social Norms to Motivate Environmental Conservation in Hotels". Journal of Consumer Research 35 (3): 472-482. 
Gottlieb, Jessica. 2016. "Common Knowledge and Voter Coordination: Experimental Evidence from Mali". In Voting Experiments, ed. by Blais, André, Laslier, Jean-François, and Straeten, Karine Van der, 89-113. Cham: Springer International Publishing. Visited on 09/16/2020. https://doi.org/10.1007/978-3-319-40573-5_5.

Gulzar, Saad, and Muhammad Yasir Khan. 2017. Why do citizens become politicians? Experimental evidence on the social dimensions of candidacy. Tech. rep. Working Paper.

Han, Kyung Joon. 2015. "The impact of radical right-wing parties on the positions of mainstream parties regarding multiculturalism". West European Politics 38 (3): 557576.

Hobolt, Sara B., and Catherine E. De Vries. 2015. "Issue Entrepreneurship and Multiparty Competition". Comparative Political Studies 48 (9): 1159-1185.

Ignazi, Piero. 1992. "The silent counter-revolution". European Journal of Political Research 22 (1): 3-34.

Imbens, Guido, and Karthik Kalyanaraman. 2012. "Optimal Bandwidth Choice for the Regression Discontinuity Estimator". The Review of Economic Studies 79 (3): 933959.

Imbens, Guido W., and Thomas Lemieux. 2008. "Regression discontinuity designs: A guide to practice". Journal of Econometrics 142 (2): 615-635.

Karp, Jeffrey A., and David Brockington. 2005. "Social desirability and response validity: A comparative analysis of overreporting voter turnout in five countries". Journal of Politics 67 (3): 825-840.

Kessler, Judd B. 2011. "Signals of support and public good provision".

Kluknavská, Alena, and Josef Smolík. 2016. "We hate them all? Issue adaptation of extreme right parties in Slovakia 1993-2016". Communist and Post-Communist Studies, The transformations of Far Right and Far Left in Europe, 49 (4): 335-344.

Kormos, Christine, Robert Gifford, and Erinn Brown. 2015. "The Influence of Descriptive Social Norm Information on Sustainable Transportation Behavior: A Field Experiment". Environment and Behavior 47 (5): 479-501.

Kuklinski, James H., Michael D. Cobb, and Martin Gilens. 1997. "Racial attitudes and the" New South"". The Journal of Politics 59 (2): 323-349.

Kuran, Timur. 1987. "Preference falsification, policy continuity and collective conservatism". The Economic Journal 97 (387): 642-665.

- 1995. Private Truths, Public Lies: The Social Consequences of Preference Falsification. Cambridge, MA: Harvard University Press.

Lange, Sarah L. de, and David Art. 2011. "Fortuyn versus Wilders: An Agency-Based Approach to Radical Right Party Building". West European Politics 34 (6): 12291249.

Lee, David S., and Thomas Lemieux. 2010. "Regression Discontinuity Designs in Economics". Journal of Economic Literature 48 (2): 281-355. Visited on 07/26/2019. https://www . aeaweb.org/articles?id=10.1257/jel.48.2.281.

March, Luke. 2011. Radical Left Parties in Europe. 1 edition. New York: Routledge. 
Mareš, Miroslav, and Richard Stojar. 2016. "Extreme right perpetrators". In Understanding Lone Actor Terrorism, 82-102. Routledge.

McConahay, John B., and Joseph C. Hough. 1976. "Symbolic racism". Journal of social issues 32 (2): 23-45.

McCrary, Justin. 2008. "Manipulation of the running variable in the regression discontinuity design: A density test". Journal of Econometrics, The regression discontinuity design: Theory and applications, 142 (2): 698-714.

McDonald, Michael. 2005. "Reporting Bias". In Polling in America: An Encyclopedia of Public Opinion, ed. by Radcliff, Benjamin and Best, Samuel. Westport CT: Greenwood Press.

Mudde, Cas. 2014. "Fighting the system? Populist radical right parties and party system change". Party Politics 20 (2): 217-226.

- 2007. Populist radical right parties in Europe. Cambridge: Cambridge University Press.

— . 2004. "The populist zeitgeist". Government and Opposition 39 (4): 542-563.

— . 2013. "Three decades of populist radical right parties in Western Europe: So what?" European Journal of Political Research 52 (1): 1-19.

Noelle-Neumann, Elisabeth. 1974. "The Spiral of Silence a Theory of Public Opinion". Publisher: Oxford Academic, Journal of Communication 24 (2): 43-51. Visited on 09/21/2020. https://academic.oup.com/joc/article/24/2/43/4553587.

Norris, Pippa. 2005. Radical right: Voters and parties in the electoral market. Cambridge: Cambridge University Press.

Panagopoulos, Costas. 2010. "Affect, social pressure and prosocial motivation: Field experimental evidence of the mobilizing effects of pride, shame and publicizing voting behavior". Political Behavior 32 (3): 369-386.

Pedersen, Susanne, Alice Grønhøj, and John Thøgersen. 2015. "Following family or friends. Social norms in adolescent healthy eating". Appetite, Social Influences on Eating, 86:54-60.

Pytlas, Bartek. 2015. Radical right parties in Central and Eastern Europe: Mainstream party competition and electoral fortune. Routledge.

Riker, William H. 1986. The Art of Political Manipulation. New Haven: Yale University Press.

Rimal, Rajiv N., and Kevin Real. 2005. "How Behaviors are Influenced by Perceived Norms". Communication Research 32 (3): 389-414.

Rydgren, Jens. 2005. "Is extreme right-wing populism contagious? Explaining the emergence of a new party family". European Journal of Political Research 44:413-427.

— . 2007. "The Sociology of the Radical Right". Annual Review of Sociology 33 (1): 241262. Visited on 07/26/2019. https://doi.org/10.1146/annurev. soc.33.040406. 131752.

Schain, Indirect Effects Martin A. 2006. "The extreme-right and immigration policymaking: Measuring direct and indirect effects". West European Politics 29 (2): 270289. 
Sniderman, Paul M., Thomas Piazza, Philip E. Tetlock, and Ann Kendrick. 1991. "The New Racism". American Journal of Political Science 35 (2): 423-447.

Tankard, Margaret E., and Elizabeth Levy Paluck. 2016. "Norm Perception as a Vehicle for Social Change". Social Issues and Policy Review 10 (1): 181-211. Visited on 07/23/2019. https://spssi.onlinelibrary.wiley.com/doi/abs/10.1111/sipr. 12022.

Valentim, Vicente. 2020. "Replication Data for: Parliamentary Representation and the Normalization of Radical Right Support". Publisher: Harvard Dataverse type: dataset. Visited on 12/23/2020. https://dataverse . harvard. edu/dataset . xhtml?persistent Id= doi:10.7910/DVN/Z6S26H.

Williams, Laron K., and Guy D. Whitten. 2015. "Don't Stand So Close to Me: Spatial Contagion Effects and Party Competition". _eprint: https://onlinelibrary.wiley.com/doi/pdf/10.111 American Journal of Political Science 59 (2): 309-325. Visited on 09/21/2020. https: //onlinelibrary.wiley.com/doi/abs/10.1111/ajps.12124.

World Bank. 2018. World Bank Open Data. Visited on 10/23/2018. https : // data . worldbank.org/.

Zaller, John. 1992. The Nature and Origins of Mass Opinion. Cambridge: Cambridge University Press.

Zhirkov, Kirill. 2014. "Nativist but not alienated: A comparative perspective on the radical right vote in Western Europe". Party Politics 20 (2): 286-296. Visited on 07/18/2019. https://doi.org/10.1177/1354068813511379. 


\section{Online Appendix}

\section{A Supporting Materials for Study 1}

This Appendix provides additional information and robustness checks for the analyses carried out in Study 1. In the first place, Table A1 shows the difference between the vote share for RRPs in CSES that are included in the analyses and the official vote share for the same parties in the same elections. The vote share as reported in CSES is around 1.6 percentage points below the official share. On average, $80 \%$ of the official vote for RRPs is reported in the post-electoral surveys included in CSES.

\begin{tabular}{cccc}
\hline \hline Vote Share CSES & Official Vote & Difference & $p$-value \\
\hline 6.39 & 7.94 & -1.56 & 0.000 \\
\hline
\end{tabular}

Table A1: Difference in the vote share for RRPs in CSES and official vote (t-test).

Table A2 and A3 represent the main analyses shown in Figure 2 in Table format.

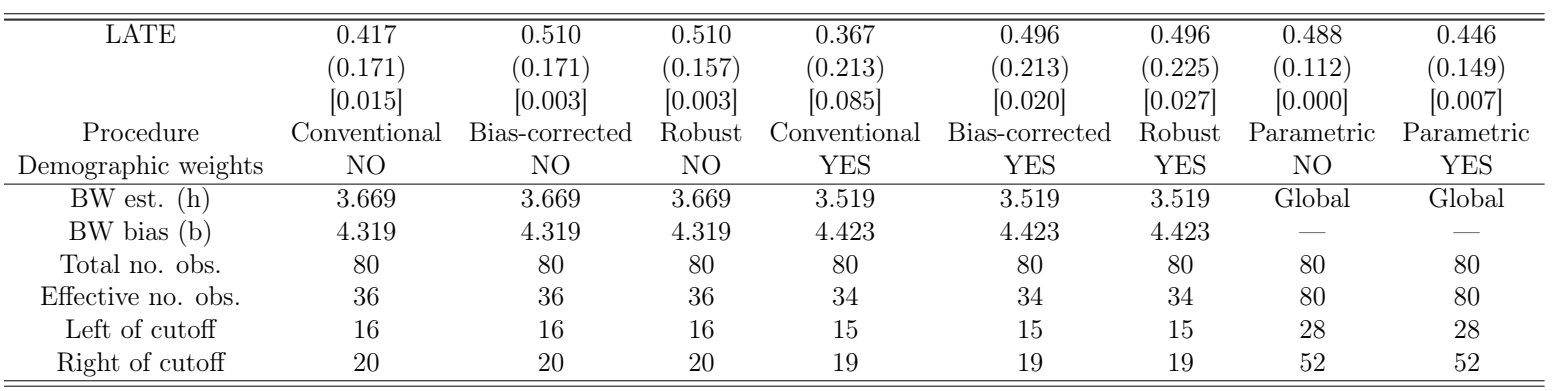

Standard errors in parentheses; $p$-values in brackets.

Standard errors are clustered by country.

Following the Akaike information criterion (AIC), the parametric models include one polynomial.

Table A18 shows the AIC for these models.

Table A2: Effect of parliamentary entry on the normalization of the radical right (regression discontinuity design).

\begin{tabular}{|c|c|c|c|c|c|c|c|c|}
\hline LATE & $\begin{array}{c}-0.124 \\
(0.276) \\
{[0.655]}\end{array}$ & $\begin{array}{c}-0.655 \\
(0.276) \\
{[0.018]}\end{array}$ & $\begin{array}{l}-0.655 \\
(0.416) \\
{[0.115]}\end{array}$ & $\begin{array}{c}-0.008 \\
(0.299) \\
{[0.978]}\end{array}$ & $\begin{array}{c}-0.499 \\
(0.299) \\
{[0.095]}\end{array}$ & $\begin{array}{l}-0.499 \\
(0.399) \\
{[0.212]}\end{array}$ & $\begin{array}{c}0.019 \\
(0.173) \\
{[0.914]}\end{array}$ & $\begin{array}{c}0.137 \\
(0.189) \\
{[0.477]}\end{array}$ \\
\hline $\begin{array}{c}\text { Procedure } \\
\text { Demographic weights }\end{array}$ & $\begin{array}{c}\text { Conventional } \\
\text { NO }\end{array}$ & $\begin{array}{l}\text { Bias-corrected } \\
\text { NO }\end{array}$ & $\begin{array}{l}\text { Robust } \\
\text { NO }\end{array}$ & $\begin{array}{c}\text { Conventional } \\
\text { YES }\end{array}$ & $\begin{array}{c}\text { Bias-corrected } \\
\text { YES }\end{array}$ & $\begin{array}{c}\text { Robust } \\
\text { YES }\end{array}$ & $\begin{array}{l}\text { Parametric } \\
\text { NO }\end{array}$ & $\begin{array}{c}\text { Parametric } \\
\text { YES }\end{array}$ \\
\hline BW est. (h) & 8.656 & 8.656 & 8.656 & 8.503 & 8.503 & 8.503 & Global & Global \\
\hline BW bias (b) & 6.095 & 6.095 & 6.095 & 5.858 & 5.858 & 5.859 & - & - \\
\hline Total no. obs. & 126 & 126 & 126 & 126 & 126 & 126 & 126 & 126 \\
\hline Left of cutoff & 14 & 14 & 14 & 14 & 14 & 14 & 14 & 14 \\
\hline Right of cutoff & 55 & 55 & 55 & 55 & 55 & 55 & 112 & 112 \\
\hline
\end{tabular}

Standard errors in parentheses; $p$-values in brackets.

Standard errors are clustered by country.

Following the Akaike information criterion (AIC), the parametric models include one polynomial.

Table A18 shows the AIC for these models.

Table A3: Placebo that replicates the main analyses using center-right, instead of radical right, parties. 
Afterwards, I test for an alternative explanation for the findings of Study 1. It might be that the results are driven not by a normalization effect, but rather by a bandwagon effect. If voters are more likely to report having voted for a successful party, and they take parliamentary presence as a proxy for success, this could explain why RRPs just above the threshold are significantly less underreported than RRPs just below the threshold. Should this be the case, however, I should be able to replicate this finding when drawing upon parties with different ideologies. Figure 2 and Tables A2 and A3 already shows that this does not happen when one draws upon center-right parties. In the following, I also replicate the main analyses focusing on left-wing, instead of right-wing parties. Unfortunately, the number of observations does not allow one to replicate the analyses using only radical left parties. For this reason, I run models that include only center-left parties (parties with a CHES score between 2 and 5.5) and models that include all leftwing parties. The results are shown in Table A4. All LATEs have the opposite direction to that found for the analyses of RRPs and none reaches traditional thresholds of statistical significance. This means that the effect shown in Figure 2 cannot be replicated when one draws upon parties that are not radical right. In other words, there is no evidence of the main results being explained by a bandwagon effect.

\begin{tabular}{ccccc}
\hline \hline & \multicolumn{2}{c}{ Non-parametric approach } & \multicolumn{2}{c}{ Parametric approach } \\
& Centre-left parties & All left-wing parties & Centre-left parties & All left-wing parties \\
\hline LATE & -1.362 & -1.287 & -1.510 & -1.389 \\
& $(1.145)$ & $(1.207)$ & $(0.894)$ & $(0.804)$ \\
BW est. (h) & {$[0.234]$} & {$[0.286]$} & {$[0.109]$} & Global \\
BW bias (b) & 6.035 & 5.375 & Global & $-101]$ \\
Total no. obs & 6.604 & 6.382 & -135 & 164 \\
Effective no. obs. & 135 & 164 & 135 & 182 \\
Left of cutoff & 66 & 86 & 117 & 142 \\
Right of cutoff & 48 & 22 & & \\
\hline \hline Standard errors in parentheses; $p$-values in brackets. & 64 & \\
Standard errors are clustered by country. & &
\end{tabular}

Table A4: Analyses using left-wing parties.

Figure A1 replicates the left-hand panel of Figure 2 using center-right, instead of radical-right, parties. As it shows, the absence of an effect is not driven by center-right parties being underreported after they enter parliament, but rather by them not being under-reported regardless of whether they enter parliament or fail to do so - if anything, there is a slight over-report of the vote for center-right parties that fail to enter parliament. 


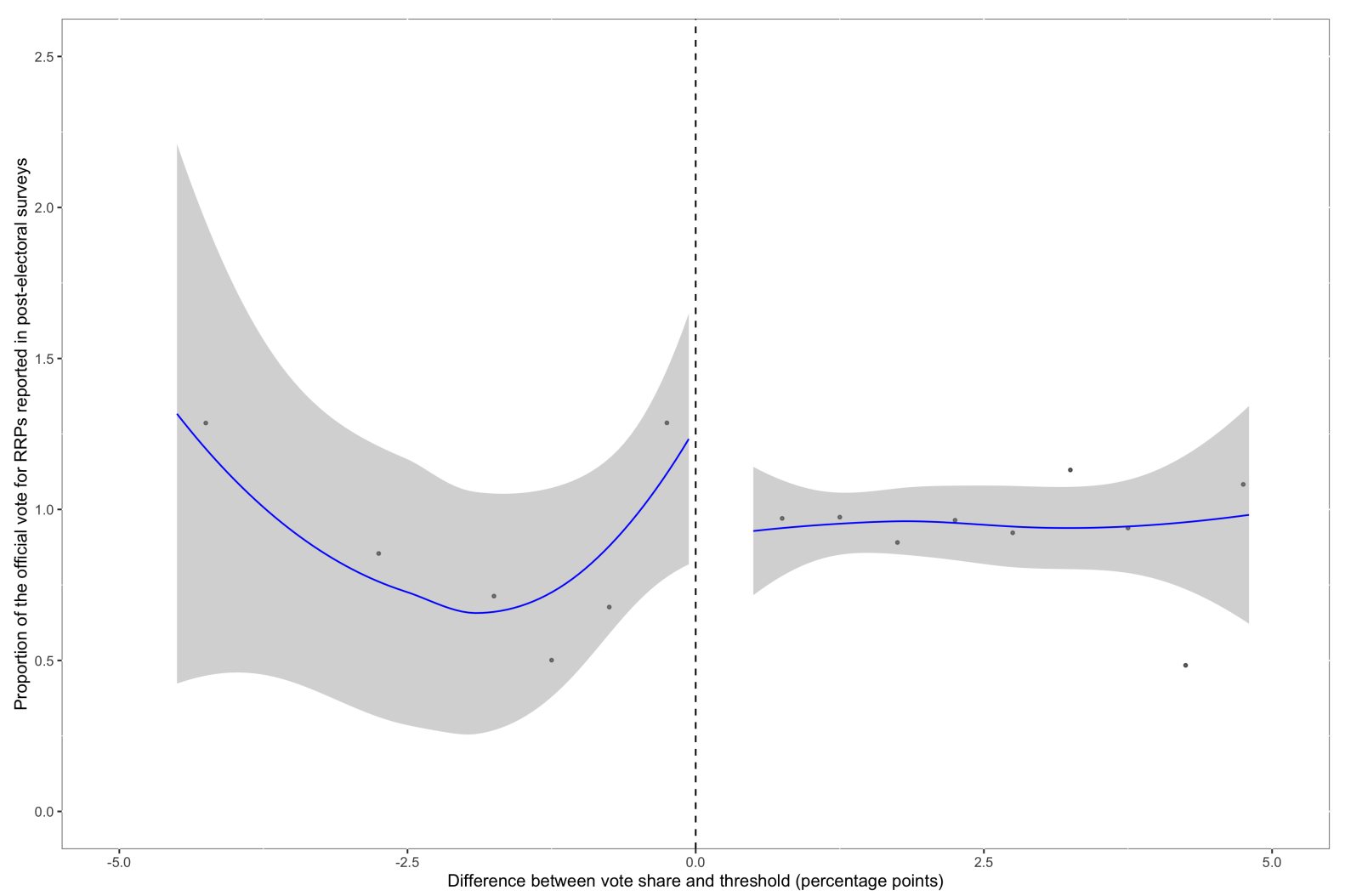

Figure A1: Replication of the left-hand panel of Figure 2 for center right, instead of radical right, parties.

Note: Shaded areas represent $95 \%$ confidence intervals. Dots represent local averages.

To check if the tendency for individuals to under-report voting for the radical right is stable throughout the time span of the study, Figure A2 shows the evolution of the proportion of the official vote for RRPs that is reported in post-electoral studies - the dependent variable in Study 1-between 2001 and 2018. There is no discernible trend in the evolution of this variable. Its value is stable throughout the period, remaining always around .8 - the average value of the variable. 


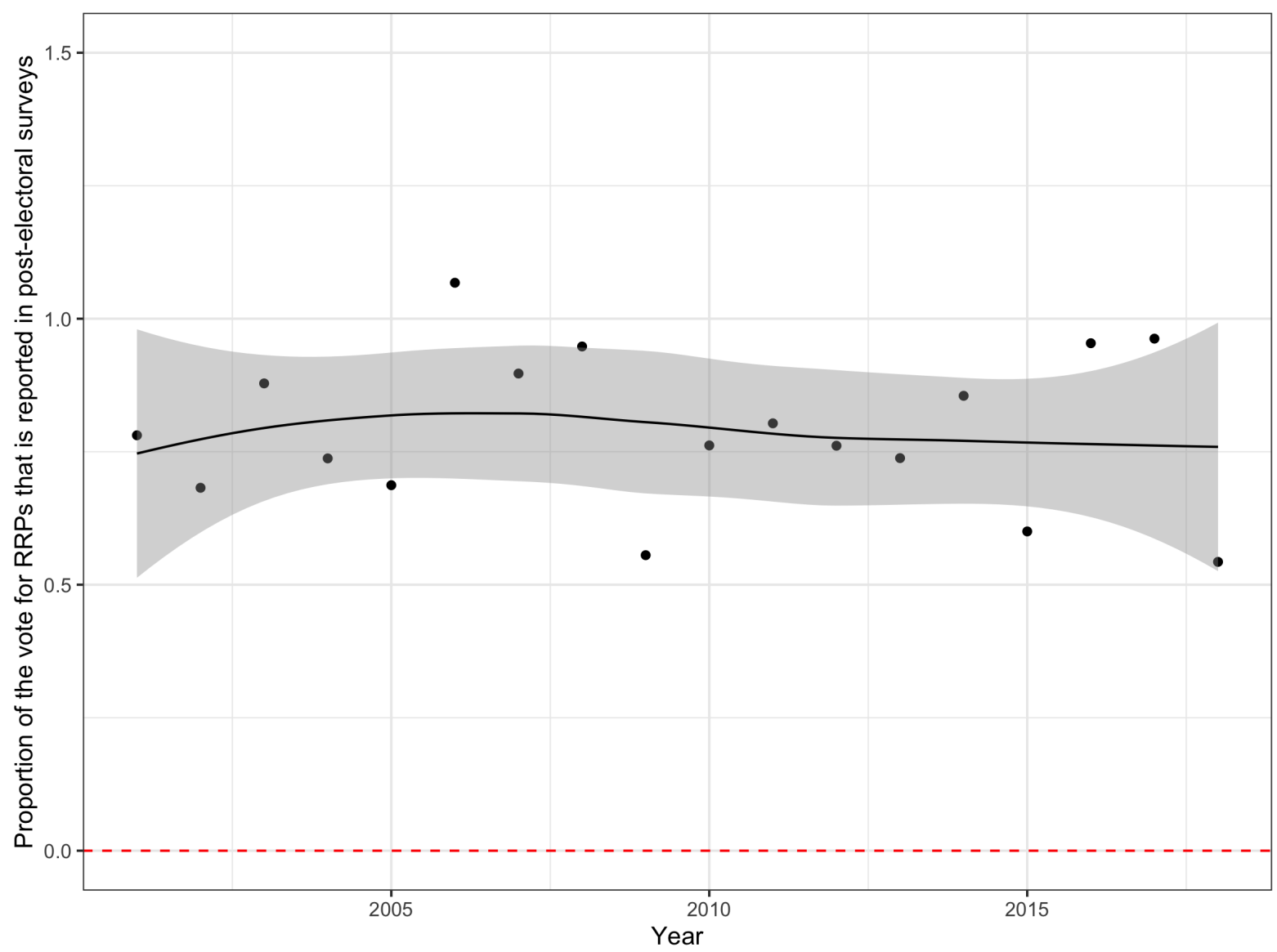

Figure A2: Evolution of the dependent variable (reported vote) through time.

Note: Shaded areas represent 95\% confidence intervals.

Table A5 shows the list of RRPs included in the analyses of Study 1, and the references that led me to code them as such. As mentioned in the text, the main references in the coding of the parties were Mudde (2007) and Norris (2005). Other references were used only for parties that became successful after these references were published and for extreme right parties - which, as discussed in footnote 3, are also included in the analyses because the argument should apply to RRPs and extreme right parties alike. 


\begin{tabular}{|c|c|}
\hline Party & Reference \\
\hline Freedom Party of Austria & Mudde (2007), Norris (2005) \\
\hline Alliance for the Future of Austria & Mudde (2007) \\
\hline Attack (Bulgaria) & Mudde (2007) \\
\hline Croatian Party of Rights & Mudde (2007) \\
\hline Czech National Party & Mudde (2007) \\
\hline Republicans (Czech Republic) & Mudde (2007), Norris (2005) \\
\hline Association for the Republic (Czech Republic) & Mudde (2007) \\
\hline Danish People's Party & Mudde (2007), Norris (2005) \\
\hline Danish Progress Party & Mudde (2007), Norris (2005) \\
\hline Estonian Independence Party & Mudde $(2007)$ \\
\hline Alternative for Germany (in 2017) & Cantoni, Hagemeister, and Westcott (2017) and Berning (2017) \\
\hline German People's Union & Mudde (2007), Norris (2005) \\
\hline The Republicans (Germany) & Mudde (2007), Norris (2005) \\
\hline National Democratic Party (Germany) & Norris $(2005)$ \\
\hline Independent Greek & Aslanidis and Rovira Kaltwasser (2016) \\
\hline Golden Dawn (Greece) & Ellinas (2013), Dinas et al. (2016), Mudde (2014), and Kluknavská and Smolík (2016) \\
\hline Popular Orthodox Rally (Greece) & Mudde (2007), Norris (2005) \\
\hline Justice and Life Party (Hungary) & Mudde (2007), Norris (2005) \\
\hline Likud (Israel) & Norris $(2005)$ \\
\hline MafDal (Israel) & Norris (2005) \\
\hline National Alliance (Italy) & Norris $(2005)$ \\
\hline Northern League (Italy) & Mudde (2007), Norris (2005) \\
\hline Brother of Italy & Gattinara (2017) \\
\hline National Alliance "All for Latvia!" & Mudde (2007) \\
\hline Center Democrats (Netherlands) & Mudde (2007), Norris (2005) \\
\hline List Pim Fortuyn (Netherlands) & Norris $(2005)$ \\
\hline Party for Freedom (Netherlands) & Mudde (2013) and Lange and Art (2011) \\
\hline Norwegian Progress Party & Norris $(2005)$ \\
\hline League of Polish Families & Mudde (2007) \\
\hline Movement for the Reconstruction of Poland & Mudde (2007) \\
\hline Greater Romania Party & Mudde (2007) \\
\hline Dveri (Serbia) & Byford (2009) \\
\hline Serbian Radical Party & Mudde (2007) \\
\hline Slovak National Party & Mudde (2007) \\
\hline People's Party Our Slovakia & Pytlas (2015) and Mareš and Stojar (2016) \\
\hline Slovenian National Party & Mudde (2007), Norris (2005) \\
\hline Swedish Democrats & Mudde (2007), Norris (2005) \\
\hline Ukrainian National Assembly & Norris $(2005)$ \\
\hline Congress of Ukrainian Nationalists & Mudde (2007) \\
\hline
\end{tabular}

Table A5: List of radical right parties included in the analyses and references according to which they belong to that party family.

One question raised by the analyses of Study 1 concerns the declared behavior of radical-right voters when the party they voted for failed to enter parliament. By design, this study allows me to know how pervasive the misreported behavior is, but not which individuals misreported their behavior. Still, in the following I show additional tests that provide some suggestive evidence to answer this question. In these tests, I use the same running variable used in Study 1 (the difference between the official vote for an RRP and the electoral threshold in the party's country). As dependent variables, I use the proportion of respondents in a given election whose response is one the survey items radical-right voters might provide as an answer, if they wanted to misrepresent their actual voting behavior: having voted for a center-right party; having voted for a center-left party; having voted for any left-wing party; ${ }^{11}$ not having turnout to vote; or choosing not to answer the question. These models identify the effect of having an RRP in parliament on the proportion of voters that gave each of these survey answers. If, when an RRP fails to make it to parliament, its voters are overwhelmingly choose one of these survey items, one should find a negative effect in the proportion of voters who provide

\footnotetext{
${ }^{11}$ There are unfortunately not enough observations to run the RDD models with radical-left parties. For this reason, I try a model that focuses solely on center-left parties and a model that draws upon all parties left-of-center.
} 
that survey item as a response.

It should be noted that, unlike the analyses shown in Figure 2 where the outcomes are measured at the party level, all the outcomes in these analyses measured at the election level: they each represent the proportion of respondents who, in a given election, gave each survey item as an answer. For this reason, I cannot include several RRPs that run for the same election. Instead, I include only the most voted RRP in each election.

The results of this exercise are shown in Figure A3. All the effects fail to reach statistical significance. One likely interpretation of this result is that when an RRP fails to make it to parliament, radical-right voters do not overwhelmingly choose another specific survey option. To the extent that the only negative effect is on the proportion of individuals who report having voted for a center-right party, one can take this as suggestive evidence that, if anything, there may be a tendency for more radical-right supporters whose party failed to enter parliament to report having voted for a centerright party. Still, such interpretation should be taken with caution, given that the effects are far from statistical significance and that this design does not allow one to know exactly who is misrepresenting their voting behavior.
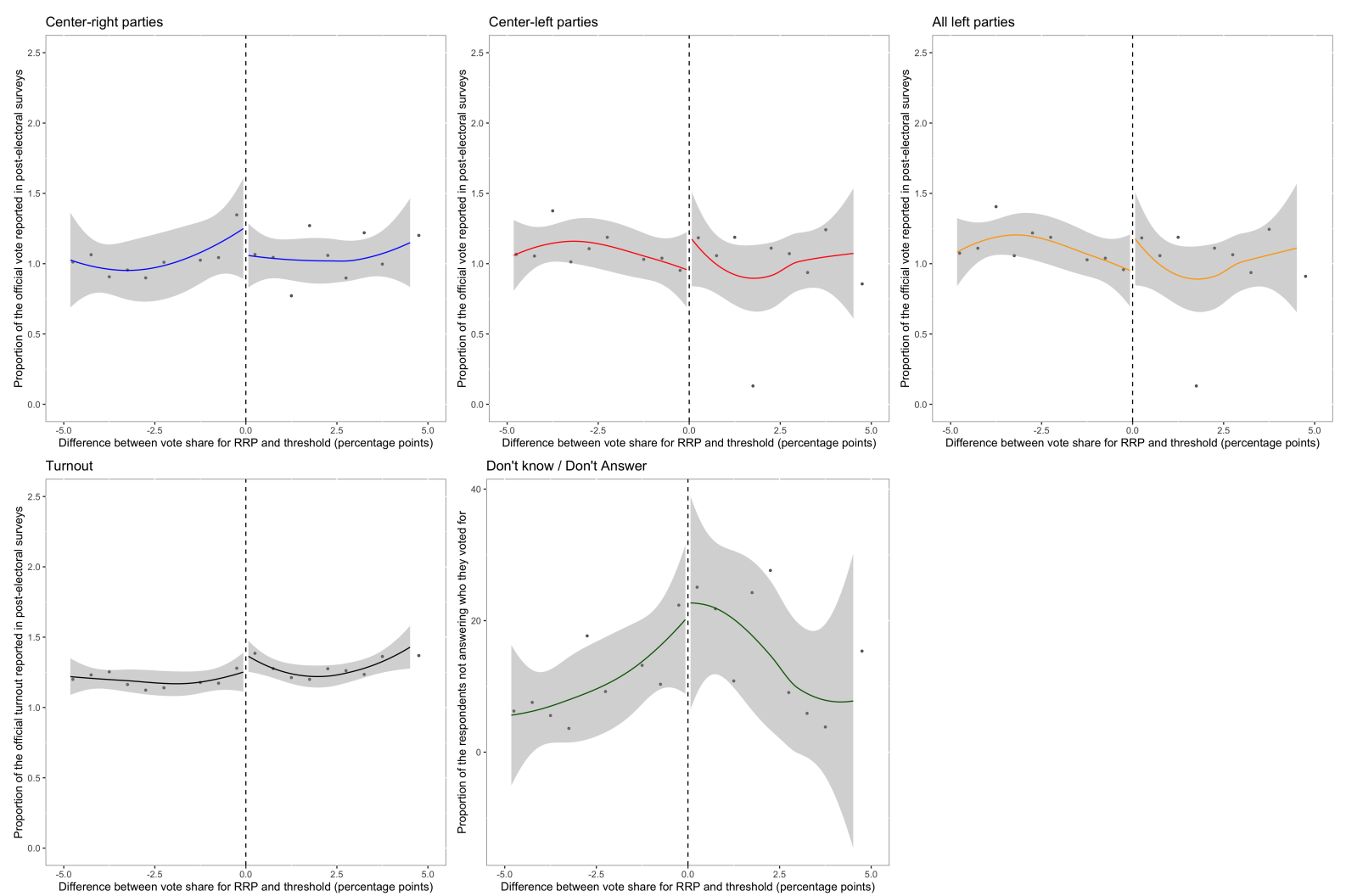

Figure A3: Effect of the parliamentary representation of an RRP on the proportion of respondents providing other survey answers.

Another question raised by the findings of Study 1 is whether the effect is stronger on parties that enter parliament for the first time. Ideally, I would like to test for this possibility by recplicating the analyses on two subsamples: one including parties that were in parliament in the previous election and one including parties that were not. Unfortunatelly, the sample size does not allow me to replicate the analyses on subsamples. 
For this reason, I report descriptive analyses that show the proportion of the official vote for RRPs that is reported in post-electoral surveys, as a function of the distance to the threshold, in both subsamples.

The results are shown in Figure A4. While these analyses are descriptive and should hence be interpreted with caution, they suggest that, if anything, the effect is stronger for RRPs that were previously in parliament and then fail to enter parliament in the current election. This suggests that voters update their perception of social norms at every election; and that entering parliament does not normalize the radical right once and for all.
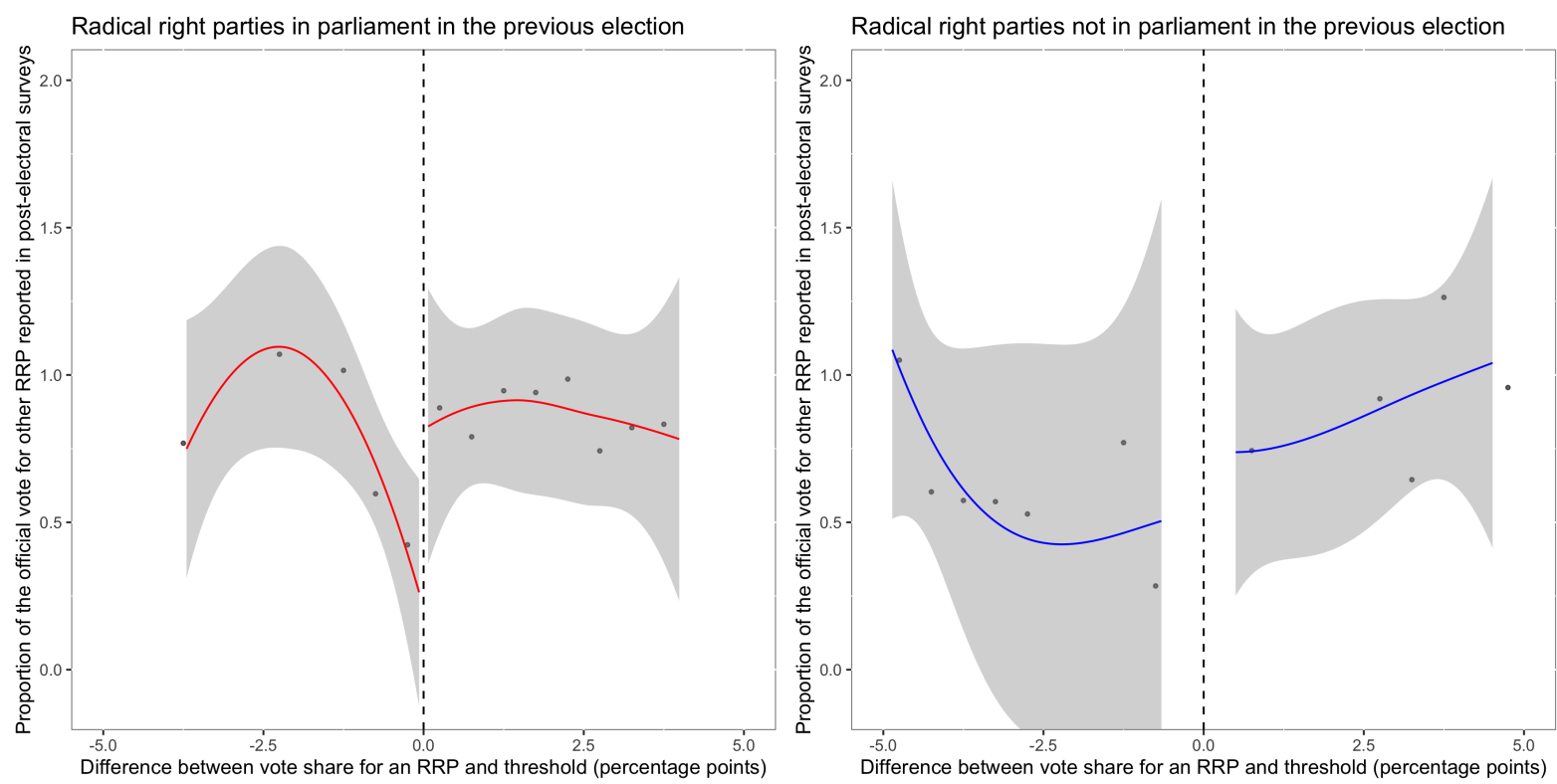

Figure A4: Proportion of the official vote for RRPs that is reported in post-electoral surveys, depending on parliamentary presence in the current and previous election.

The following analyses test whether the assumptions of the RDD are met. One such assumption is the absence of sorting. I check whether this assumption is met by running the McCrary (2008) test. The plot for this test is shown in Figure A5. I find no evidence of sorting. The $p$-value for the null of no-sorting is 0.90 . 


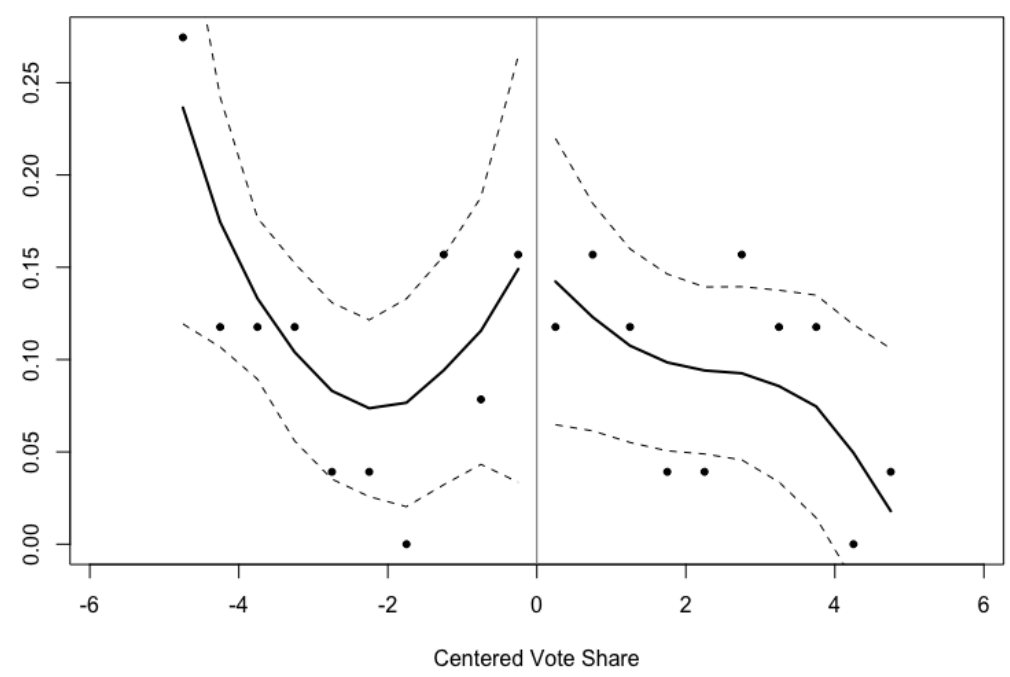

Figure A5: McCrary test for sorting around the threshold.

Given that the RDD used in Study 1 is a fuzzy RDD, another assumption is that, like in Instrumental Variable designs, there is a strong first stage. Figure A6 graphically represents the first stage of the non-parametric RDD shown in Figure 2 for the analyses of RRPs. In the control group, the likelihood of having parliamentary representation is not always 0 , as some parties do enter parliament despite failing to reach the electoral threshold. However, it is always low - its highest peak is just above 30 percent. In turn, in the treatment group all units have a $100 \%$ probability of having parliamentary representation, as all parties in the dataset with a vote share that is above the electoral threshold entered their country's parliament. There is a large discontinuity in the probability of treatment when parties cross the threshold. 


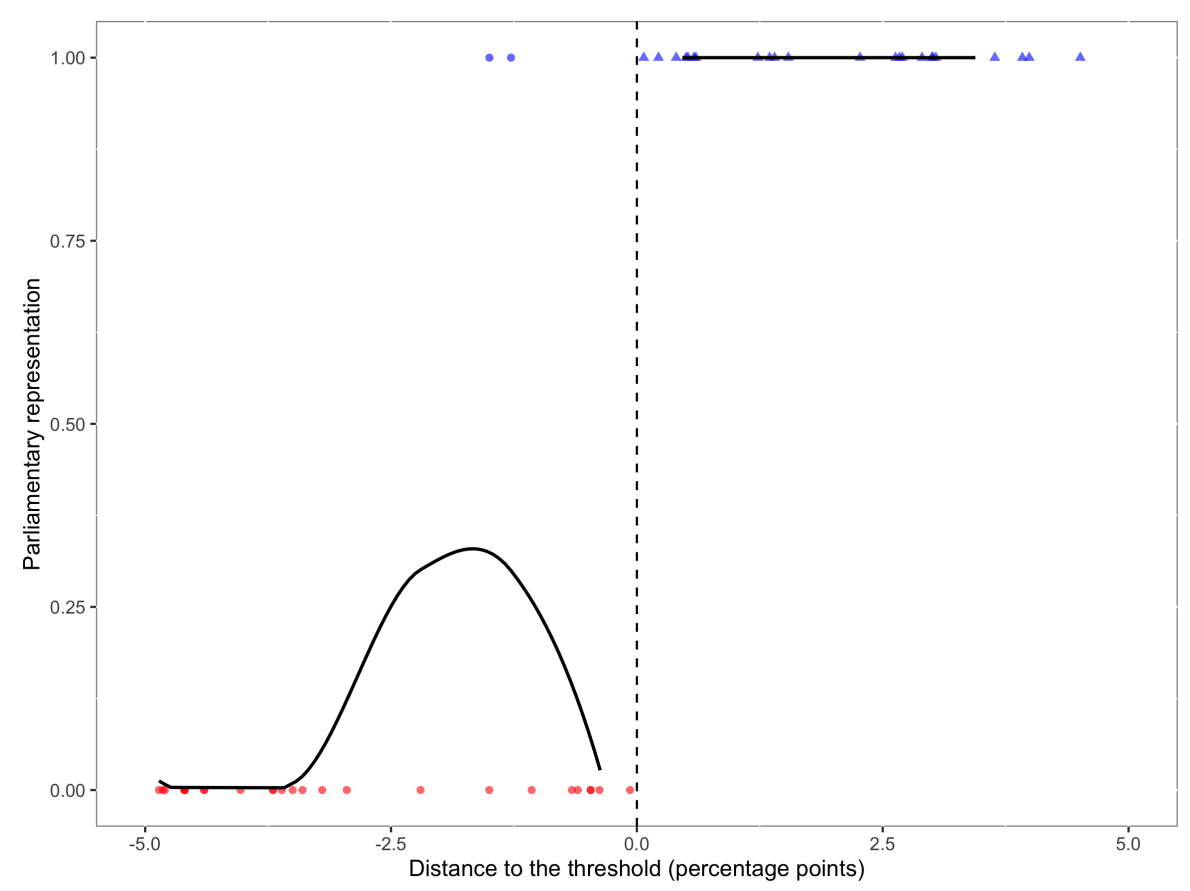

Figure A6: Graphical representation of the first stage in the fuzzy RDD.

Notes: Red dots represent parties failing to enter parliament; blue dots represent parties entering parliament. Circles represent parties whose vote share is lower than the threshold; triangles represent parties whose vote share is higher than the threshold.

In the following, I look carefully at a potential alternative explanation referred to in the main text. It is possible that the results are being driven not by the perceived lower strength of the social norm but by the fact that, after an RRP enters parliament, the individuals who are successfully contacted to answer post-electoral surveys have different characteristics. The main analyses shown in Figure 2 include models with sociodemographic controls to decrease concerns that imbalances in the demographic characteristics of respondents may be driving the results. Below I provide another test to rule out this alternative explanation. I replicate the regression discontinuity shown in Figure 2, using sociodemographic variables as dependent variables: median age, percentage of women, and household income. For each of these variables, I took the values from CSES surveys and subtracted them to official data for each country. ${ }^{12}$ The only exception was household income. Because this variable is coded as quintiles in CSES, I simply took the variable as it is, without subtracting it to another value.

The results are shown in Table A6. All LATEs are small and far from traditional thresholds of statistical significance. The fact that there are no differences in the demographic characteristics of respondents when RRPs are above and below the threshold provides further certainty that the results are not being driven by such differences.

\footnotetext{
${ }^{12}$ Data for median age was retrieved from the website of the Global Health Observatory (2018); data for the percentage of women was retrieved from the website of the World Bank (2018). In both cases, when data was not available for the election year itself, I took the year closest to it for which data was available.
} 


\begin{tabular}{ccccccc}
\hline \hline & \multicolumn{3}{c}{ Non-parametric approach } & \multicolumn{3}{c}{ Parametric approach } \\
& Median age & \% Women & Household income & Median age & \% Women & Household income \\
\hline LATE & -0.643 & -1.467 & -0.025 & -0.334 & 0.549 & -0.080 \\
& $(5.998)$ & $(2.372)$ & $(0.085)$ & $(3.032)$ & $(1.159)$ & $(0.100)$ \\
& {$[0.915]$} & {$[0.536]$} & {$[0.771]$} & {$[0.913]$} & {$[0.641]$} & {$[0.431]$} \\
\hline BW est. (h) & 2.512 & 2.718 & 4.902 & Global & Global & Global \\
BW bias (b) & 3.269 & 3.563 & 6.229 & - & - & -79 \\
Total no. obs. & 80 & 80 & 79 & 80 & 80 & 79 \\
Effective no. obs. & 23 & 26 & 50 & 80 & 80 & 28 \\
Left of cutoff & 11 & 11 & 28 & 28 & 28 & 51 \\
Right of cutoff & 12 & 15 & 22 & 52 & 52 & 79 \\
\hline \hline
\end{tabular}

Standard errors in parentheses; $p$-values in brackets.

Standard errors are clustered by country.

Following the Akaike information criterion (AIC), the parametric models include one polynomial.

Table A20 shows the AIC for these models.

The non-parametric models are robust (Calonico et al. 2017).

Table A6: Analyses with sociodemographic variables as dependent variables.

I test for another potential alternative explanation. It could be argued that the normalizing effect I am capturing is not really driven by the parliamentary entry of an RRP, but rather by the ideological placement of mainstream parties. If mainstream parties in a given system are more rightist, individuals may feel more comfortable in engaging in public demonstrations of support to the radical right because the overall position of the party system makes the position of RRPs seem less radical. To test for this possibility, Figure A7 plots the left-right mean of the whole ideological spectrum against the dependent variable in the main analysis of Study 1 (reported vote for RRPs). The left-right mean was calculated based on data from the CHES, weighted by the official vote for each RRP. The figure shows no discernible association between the two variables. 


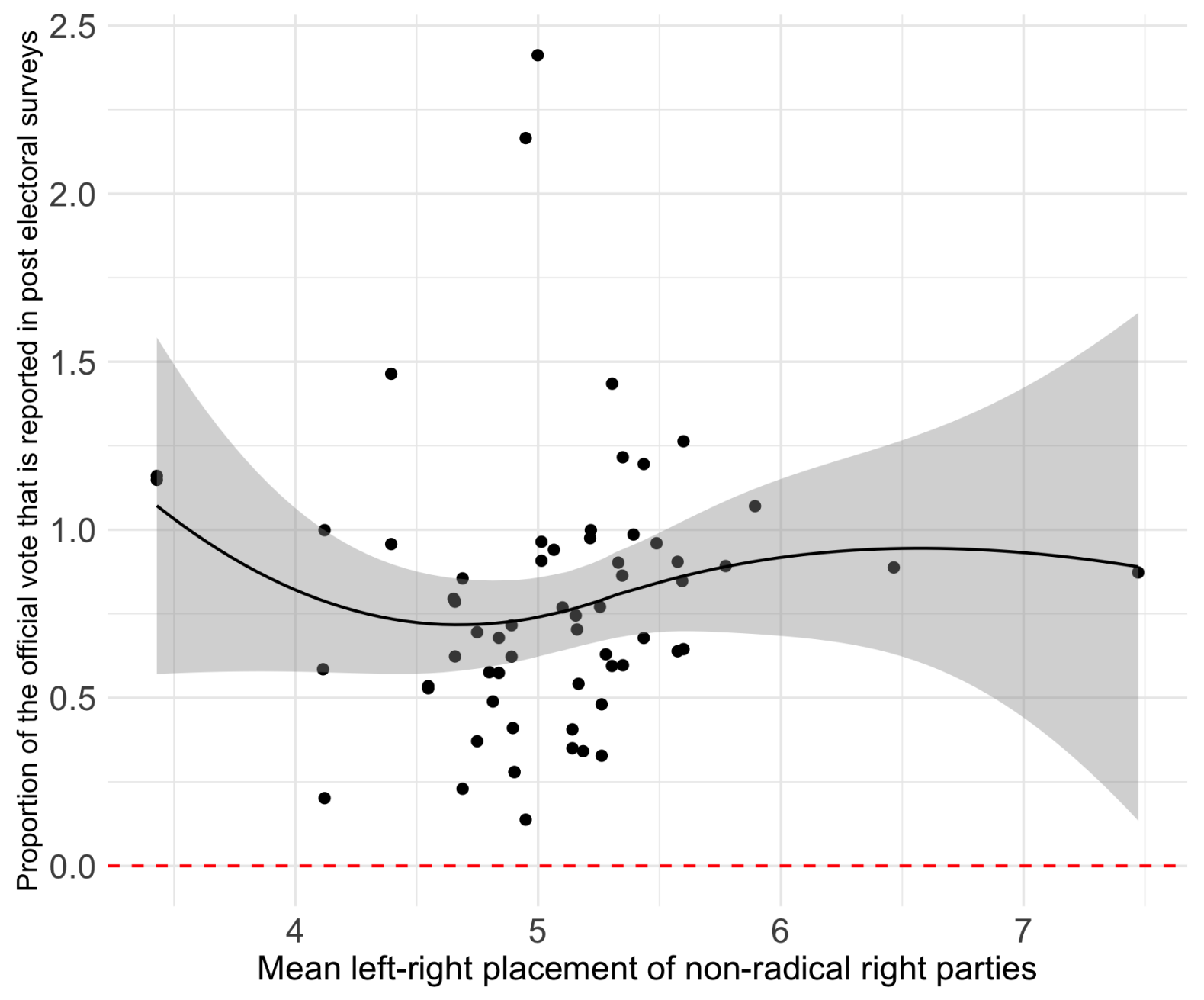

Figure A7: Association between the mean ideological position of the party system and dependent variable (reported vote).

Finally, it could be argued that RRPs that make it to parliament are more moderate than the ones that do not make it. To test for this, replicate the analyses shown in Figure 2, using the CHES left-right placement of parties as the dependent variable. The results are shown in Table A7. While RRPs seem to be slightly more moderate if their vote share is higher and if they make it to parliament, the coefficients using both the parametric and non-parametric approach fail to reach statistical significance. 


\begin{tabular}{ccc}
\hline \hline & Non-parametric approach & Parametric approach \\
\hline LATE & -1.691 & -0.496 \\
& $(1.341)$ & $(0.472)$ \\
& {$[0.207]$} & {$[0.308]$} \\
\hline BW est. (h) & 5.453 & Global \\
BW bias (b) & 5.149 & - \\
Total no. obs & 63 & 63 \\
Effective no. obs. & 42 & 63 \\
Left of cutoff & 21 & 21 \\
Right of cutoff & 21 & 42 \\
\hline \hline
\end{tabular}

Standard errors in parentheses; $p$-values in brackets.

Standard errors are clustered by country.

Following the Akaike information criterion (AIC), the parametric model includes one polynomial.

Table A21 shows the AIC for these models.

The non-parametric model is robust (Calonico et al. 2017).

Table A7: Effect of parliamentary entry on the left-right placement of RRPs.

I then run a number of robustness checks. In the first place, I run the non-parametric analyses shown in Figure 2 for RRPs again, changing the bandwidth. I try all bandwidths between 2.5 percentage points and 7.5 percentage points, with intervals of 0.1 percentage points. Figure A8 shows the LATE at each of these bandwidths, for the three estimation procedures: conventional, bias-corrected and robust. Regardless of the bandwidth and procedure used, the LATEs remains above 35 percentage points, and the large majority remains statistically significant at the $90 \%$ level.
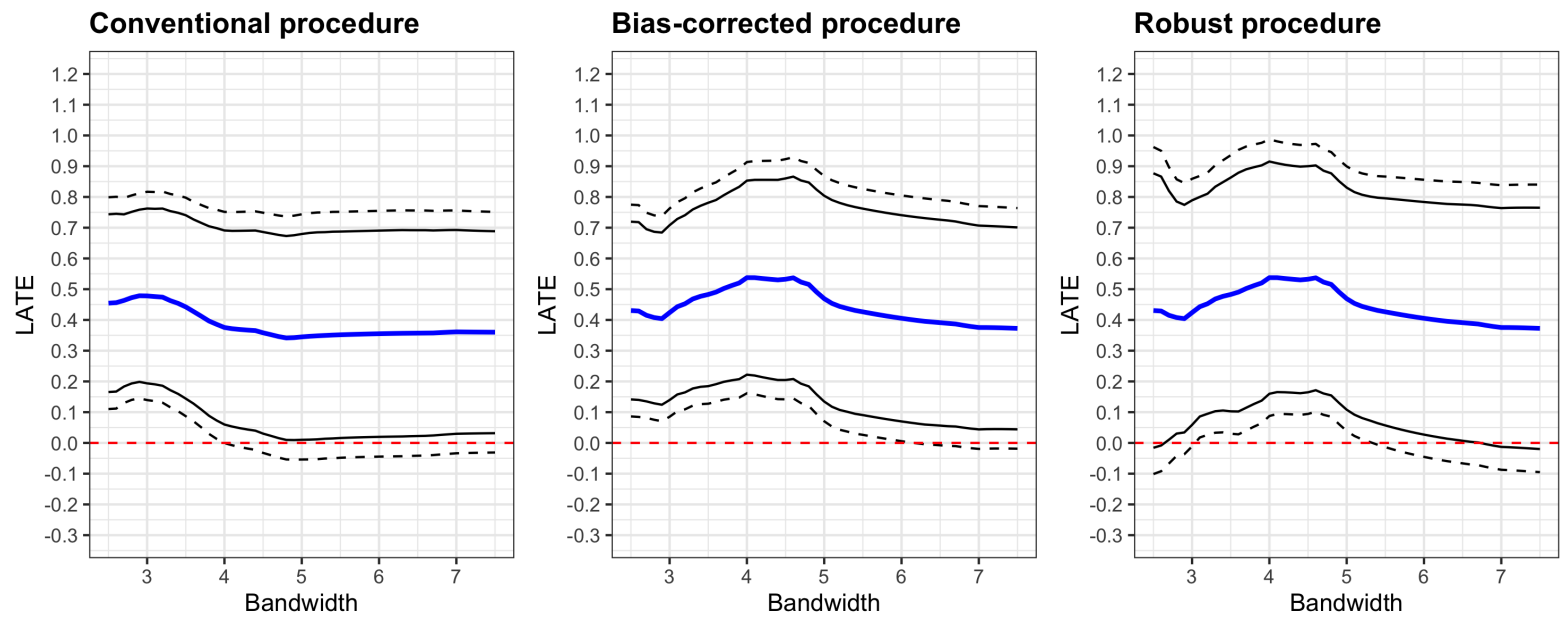

Figure A8: LATE at varying bandwidths.

Note: Solid lines represent $90 \%$ confidence intervals; dashed lines represent $95 \%$ confidence intervals. Standard errors are clustered by country.

Given the relatively low number of observations in the regression discontinuity, it is crucial to make sure that the findings are not being driven by influential country cases. I check for that by replicating the analyses sequentially removing one country at a 
time. I do this using a parametric approach and three sets of non-parametric approaches: robust, bias-corrected, and conventional. The results of this exercise are shown in Figure A9. In these 84 models, only one fails to reach statistical significance at the $90 \%$ level: the conventional model excluding Serbia. However, the LATE for the three remaining analyses excluding this country remain statistically significant.

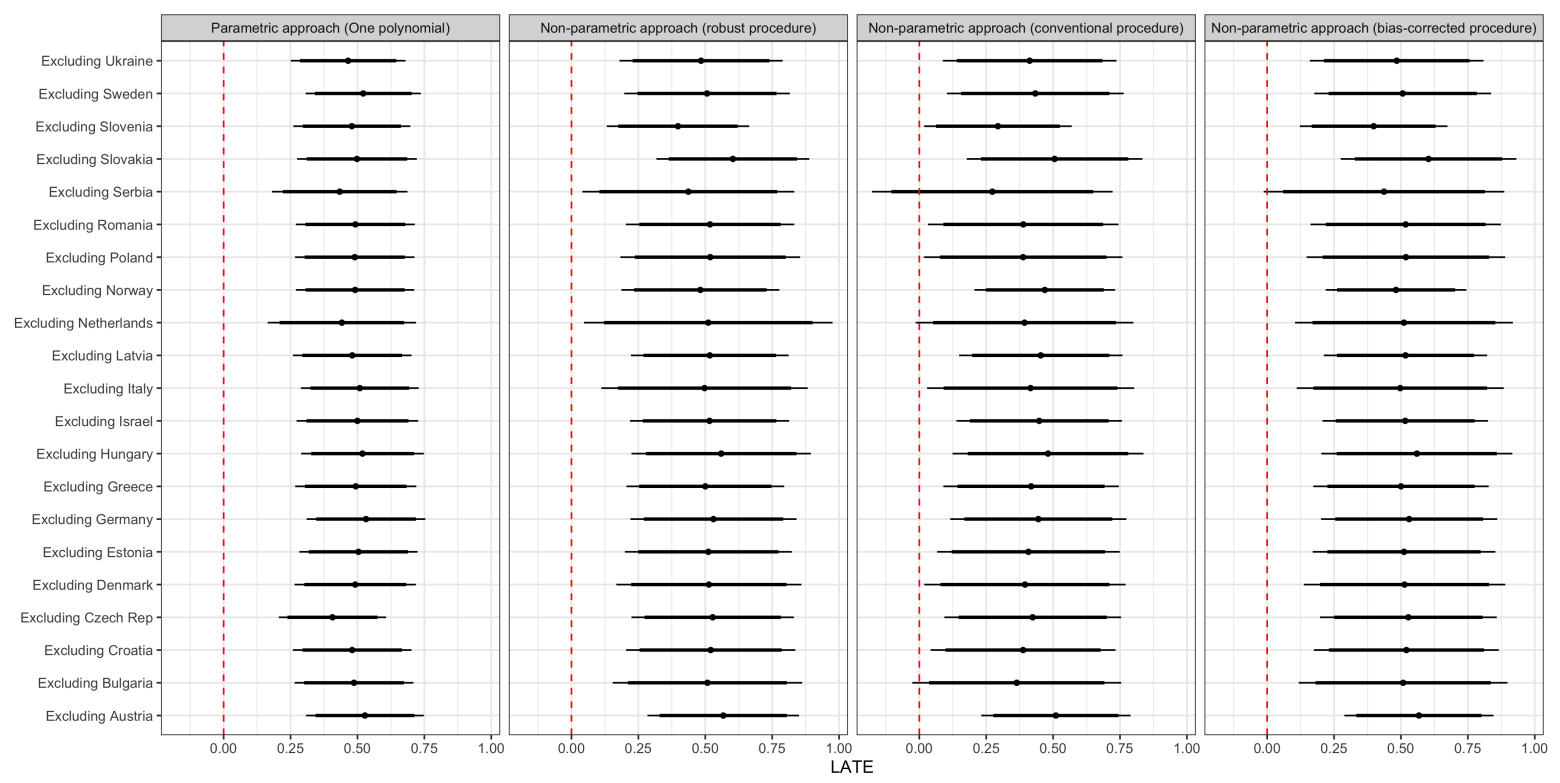

Figure A9: Replication of the analyses after removing one country at a time.

Note: Thick lines represent $90 \%$ confidence intervals; thin lines represent $95 \%$ confidence intervals. Standard errors are clustered by country. Following the Akaike Information Criterion, the parametric models include one polynomial.

The coding of parties as RRPs is mainly based on two references: Mudde (2007) and Norris (2005). Most parties considered to be an RRP by one author are also considered as such by another author. Most parties that are considered as an RRP by one of these references alone exist in countries that are not considered in the other author's study (for example, Mudde draws exclusively upon European parties, which means that his study does not considered Israel, a country that is included in Norris's work). Still, there are discrepancies in the coding of a handful of parties, which raise the question of whether these parties are driving the results. In the following, I explicitly address this concern, by replicating the main analyses after removing parties that are considered to be an RRP by Norris (2005), but not by Mudde (2007); and parties that are considered to be an RRO by Mudde (2007) but not by Norris (2005). The results are shown in Table A8. All models remain statistically significant, and the magnitude of the effects is similar to that shown in Figure 2. 


\begin{tabular}{|c|c|c|c|c|}
\hline & \multicolumn{2}{|c|}{ Non-parametric approach } & \multicolumn{2}{|c|}{ Parametric approach } \\
\hline & Parties not in Mudde 2007 & Parties not in Norris 2005 & Parties not in Mudde 2007 & Parties not in Norris 2005 \\
\hline \multirow[t]{3}{*}{ LATE } & 0.478 & 0.546 & 0.440 & 0.447 \\
\hline & $(0.149)$ & $(0.146)$ & $(0.131)$ & $(0.094)$ \\
\hline & {$[0.001]$} & {$[0.000]$} & {$[0.003]$} & {$[0.000]$} \\
\hline BW est. (h) & 2.660 & 3.751 & Global & Global \\
\hline BW bias (b) & 3.367 & 4.159 & - & - \\
\hline Total no. obs & 68 & 76 & 68 & 76 \\
\hline Effective no. obs. & 24 & 36 & 68 & 76 \\
\hline Left of cutoff & 11 & 16 & 21 & 24 \\
\hline Right of cutoff & 13 & 20 & 47 & 52 \\
\hline \multicolumn{5}{|c|}{ Standard errors in parentheses; $p$-values in brackets. } \\
\hline \multicolumn{5}{|c|}{ Standard errors are clustered by country. } \\
\hline \multirow{2}{*}{\multicolumn{5}{|c|}{$\begin{array}{l}\text { Following the Akaike information criterion (AIC), the parametric models include one polynomial. } \\
\text { Table A22 shows the AIC for these models. }\end{array}$}} \\
\hline & & & & \\
\hline
\end{tabular}

Table A8: Replication of the main analyses after removing parties coded differently by Mudde (2007) and Norris (2005).

I also replicate the main analyses with different specifications. In the main analyses shown in Figure 2, the dependent variable is the proportion of the official vote for each party that is reported in post-electoral surveys. In the following, I replicate these analyses using simply the vote share for each RRP in post-electoral surveys as the dependent variable. If individuals feel more confident in publicly displaying support for RRPs just above the electoral threshold than just below that threshold, one should find a discontinuity with this specification as well. The results are shown in Table A9. They show that there is a significant discontinuity around the electoral threshold. Depending on the approach, RRPs just above that threshold have a vote share in CSES that is between 1.8 and 2.2 percentage points higher than those of parties just below the threshold.

\begin{tabular}{ccc}
\hline \hline & Non-parametric approach & Parametric approach \\
\hline LATE & 2.174 & 1.782 \\
& $(0.809)$ & $(0.657)$ \\
& {$[0.007]$} & {$[0.013]$} \\
\hline BW est. (h) & 3.034 & Global \\
BW bias (b) & 4.010 & - \\
Total no. obs & 80 & 80 \\
Effective no. obs. & 30 & 80 \\
Left of cutoff & 12 & 27 \\
Right of cutoff & 18 & 53 \\
\hline \hline
\end{tabular}

Standard errors in parentheses; $p$-values in brackets.

Standard errors are clustered by country.

Following the Akaike information criterion (AIC), the parametric model includes one polynomial.

Table A23 shows the AIC for these models.

The non-parametric model is robust (Calonico et al. 2017).

Table A9: Analyses with the vote share for each RRP in CSES as the dependent variable.

The main analyses in Study 1 include some parties that ran for the same election. That is because the argument put forward in the paper regards each RRP itself: the parliamentary entry of one of these parties should signal to voters that the views of that party specifically have been normalized. One potential concern about these analyses is 
that there may be a spillover effect. Previous research has found that the performance of one party can affect voter behavior toward spatially close parties (Williams and Whitten 2015). Following this literature, one might expect that the parliamentary presence of one RRP might make voters of another party perceive that it, too, has been normalized.

I tackle this concern in three ways. In the first place, I replicate the analyses shown in Table A2 using an alternative dependent variable: the overall reported vote for RRPs as the dependent variable. As shown in Table A10, the results remain very similar to the main ones.

\begin{tabular}{ccc}
\hline \hline & Non-parametric approach & Parametric approach \\
\hline LATE & 0.477 & 0.772 \\
& $(0.196)$ & $(0.234)$ \\
& {$[0.015]$} & {$[0.004]$} \\
\hline BW est. (h) & 3.572 & Global \\
BW bias (b) & 4.616 & - \\
Total no. obs & 80 & 80 \\
Effective no. obs. & 34 & 80 \\
Left of cutoff & 15 & 28 \\
Right of cutoff & 19 & 52 \\
\hline \hline
\end{tabular}

Standard errors in parentheses; $p$-values in brackets.

Standard errors are clustered by country.

Following the Akaike information criterion (AIC), the parametric model includes one polynomial.

Table A24 shows the AIC for these models.

The non-parametric models are robust (Calonico et al. 2017).

Table A10: Analyses using the overall reported vote for RRPs as the dependent variable.

In the second place, I replicate the main analyses shown in Figure 2 including a control variable for the sum of the vote share for all RRPs in each election. The results of this exercise are shown in Table A11. Both the parametric and the non-parametric models remain statistically significant, and their coefficient sizes remain identical to those shown in Figure 2. 


\begin{tabular}{ccc}
\hline \hline & Non-parametric approach & Parametric approach \\
\hline LATE & 0.494 & 0.489 \\
& $(0.172)$ & $(0.112)$ \\
& {$[0.004]$} & {$[0.000]$} \\
\hline BW est. (h) & 3.671 & Global \\
BW bias (b) & 4.355 & - \\
Total no. obs & 80 & 80 \\
Effective no. obs. & 36 & 80 \\
Left of cutoff & 16 & 28 \\
Right of cutoff & 20 & 52 \\
\hline \hline
\end{tabular}

Standard errors in parentheses; $p$-values in brackets.

Standard errors are clustered by country.

Following the Akaike information criterion (AIC), the parametric model includes one polynomial.

Table A25 shows the AIC for these models.

The non-parametric model is robust (Calonico et al. 2017).

All models include controls for the sum of vote shares by RRPs in that election.

Table A11: Analyses including a control for the overall vote share for RRPs in each election.

Finally, I replicate the analyses using only the most successful party in each country. The results are shown in Table A12. The LATE of the parametric model is larger than the ones shown in Figure 2 and the LATE from the non-parametric model is similar in magnitude to those - even if, with the smaller sample size, the latter fails to reach statistical significance.

\begin{tabular}{ccc}
\hline \hline & Non-parametric approach & Parametric approach \\
\hline LATE & 0.372 & 0.921 \\
& $(0.319)$ & $(0.276)$ \\
& {$[0.243]$} & {$[0.003]$} \\
\hline BW est. (h) & 5.239 & Global \\
BW bias (b) & 6.029 & - \\
Total no. obs & 58 & 58 \\
Effective no. obs. & 33 & 58 \\
Left of cutoff & 16 & 16 \\
Right of cutoff & 17 & 42 \\
\hline \hline
\end{tabular}

Standard errors in parentheses; $p$-values in brackets.

Standard errors are clustered by country.

Following the Akaike information criterion (AIC), the parametric model includes three polynomials.

Table A26 shows the AIC for these models.

The non-parametric models are robust (Calonico et al. 2017).

Table A12: Analyses using only the most voted RRP in each election.

Following the work by Duverger (1954), electoral systems have been widely regarded as significantly constraining the voting choices of individuals and the extent to which they can express their preferences. If the districts are smaller, the RRPs may be more 
likely to enter parliament and, at the same time, the voters may feel like the system is more responsive to their views, which may make them more likely to report their private preferences. For this reason, Table A13 replicates the main analyses controlling for the average district magnitude in each election, using data from the V-Dem Project (Coppedge et al. 2017). The results remain statistically significant and the effect sizes remain comparable.

\begin{tabular}{ccc}
\hline \hline & Non-parametric approach & Parametric approach \\
\hline LATE & 0.289 & 0.552 \\
& $(0.148)$ & $(0.119)$ \\
& {$[0.051]$} & {$[0.000]$} \\
\hline BW est. (h) & 4.852 & Global \\
BW bias (b) & 5.619 & - \\
Total no. obs & 61 & 61 \\
Effective no. obs. & 34 & 61 \\
Left of cutoff & 13 & 14 \\
Right of cutoff & 21 & 47 \\
\hline \hline
\end{tabular}

Standard errors in parentheses; $p$-values in brackets.

Standard errors are clustered by country.

Following the Akaike information criterion (AIC), the parametric model includes one polynomial.

Table A27 shows the AIC for these models.

The non-parametric model is robust (Calonico et al. 2017).

Table A13: Analyses controlling for district magnitude.

Tables A14 and A15 replicate the main analyses including country fixed effects and survey wave fixed effects, respectively. It should be noted that the analyses including country fixed effects were performed using the RDEstimate function in the rdd package for $\mathrm{R}$ instead of the rdrobust package, which was used in the main analyses in the text. That is because the sample size is too small for rdrobust to be able to perform the analyses with country fixed effects. For this reason, the non-parametric model uses the Imbens-Kalyanaraman optimal bandwidth (Imbens and Kalyanaraman 2012), which also explains why only one bandwidth is reported. The results hold after the inclusion of these two sets of fixed effects. 


\begin{tabular}{ccc}
\hline \hline & Non-parametric approach & Parametric approach \\
\hline LATE & 0.637 & 0.403 \\
& $(0.323)$ & $(0.135)$ \\
& {$[0.049]$} & {$[0.007]$} \\
\hline Bandwidth & 4.505 & Global \\
Total no. obs & 80 & 80 \\
Effective no. obs. & 43 & 80 \\
Left of cutoff & 21 & 28 \\
Right of cutoff & 22 & 52 \\
\hline \hline
\end{tabular}

Standard errors in parentheses; $p$-values in brackets.

Standard errors are clustered by country.

Following the Akaike information criterion (AIC), the parametric model includes one polynomial.

Table A28 shows the AIC for these models.

The non-parametric models are robust (Calonico et al. 2017).

Table A14: Analyses including country fixed effects.

\begin{tabular}{ccc}
\hline \hline & Non-parametric approach & Parametric approach \\
\hline LATE & 0.480 & 0.521 \\
& $(0.194)$ & $(0.125)$ \\
& {$[0.013]$} & {$[0.000]$} \\
\hline BW est. (h) & 4.889 & Global \\
BW bias (b) & 4.888 & - \\
Total no. obs & 80 & 80 \\
Effective no. obs. & 43 & 80 \\
Left of cutoff & 28 & 28 \\
Right of cutoff & 23 & 52 \\
\hline \hline
\end{tabular}

Standard errors in parentheses; $p$-values in brackets.

Standard errors are clustered by country.

Following the Akaike information criterion (AIC), the parametric model includes one polynomial.

Table A29 shows the AIC for these models.

The non-parametric models are robust (Calonico et al. 2017).

Table A15: Analyses including survey wave fixed effects.

As discussed in footnote 3, Alternative for Germany (AfD) was coded as an RRP only in the election of 2017. That is because most literature tends to consider that the party was not radical right in the previous election, held in 2013. To make sure this decision is not driving the result, I replicate the analyses coding AfD as an RRP in 2013 too. The results, shown in Table A16 show that the results are similar and remain statistically significant. 


\begin{tabular}{ccc}
\hline \hline & Non-parametric approach & Parametric approach \\
\hline LATE & 0.403 & 0.427 \\
& $(0.210)$ & $(0.130)$ \\
& {$[0.056]$} & {$[0.004]$} \\
\hline BW est. (h) & 3.772 & Global \\
BW bias (b) & 4.247 & - \\
Total no. obs & 81 & 81 \\
Effective no. obs. & 39 & 80 \\
Left of cutoff & 19 & 29 \\
Right of cutoff & 20 & 52 \\
\hline \hline
\end{tabular}

Standard errors in parentheses; $p$-values in brackets.

Standard errors are clustered by country.

Following the Akaike information criterion (AIC), the parametric model includes one polynomial.

Table A30 shows the AIC for these models.

The non-parametric model is robust (Calonico et al. 2017).

Table A16: Analyses coding AfD as an RRP both in 2017 and in 2013.

Finally, it is important to check the extent to which the findings of the RDD using parametric regression are sensitive to the order of the polynomial used (Lee and Lemieux 2010, p. 324). To do so, I replicate the main findings using a parametric approach, as shown in Figure 2, changing the number of polynomials included in the models. The findings shown in Figure 2 include one polynomial; here I replicate the findings using up to four polynomials. The results remain substantively similar.

\begin{tabular}{lcccc}
\hline \hline & One polynomial & Two polynomials & Three polynomials & Four polynomials \\
\hline LATE & 0.488 & 0.433 & 0.847 & 0.845 \\
& $(0.113)$ & $(0.177)$ & $(0.205)$ & $(0.207)$ \\
& {$[0.000]$} & {$[0.023]$} & {$[0.001]$} & {$[0.001]$} \\
\hline Total no. obs & 80 & 80 & 80 & 80 \\
Effective no. obs. & 80 & 80 & 80 & 80 \\
Left of cutoff & 28 & 28 & 28 & 28 \\
Right of cutoff & 52 & 52 & 52 & 52 \\
\hline \hline
\end{tabular}

Standard errors in parentheses; $p$-values in brackets.

Standard errors are clustered by country.

The non-parametric models are robust (Calonico et al. 2017).

Table A17: Analyses using parametric models with different number of polynomials.

In all the parametric models shown up to here include, the number of polynomials was chosen according to the Akaike Information Criterion (AIC), as suggested by Lee and Lemieux (2010, p. 326). The following tables report these tests for each of the models. 


\begin{tabular}{ccccc}
\hline \hline & \multicolumn{2}{c}{ Radical Right Parties } & \multicolumn{2}{c}{ Center Right Parties } \\
Unweighted & $\begin{array}{c}\text { Weighted } \\
\text { Unweighted }\end{array}$ & Weighted \\
Number of polynomials & & \multicolumn{2}{c}{ AIC } \\
\hline One & 71.70587 & 74.34086 & 37.84144 & 35.08194 \\
Two & 74.14394 & 75.90258 & 38.53474 & 36.24348 \\
Three & 74.31564 & 74.88244 & 40.30092 & 37.63212 \\
Four & 76.30806 & 76.75211 & 39.7798 & 37.52313 \\
\hline \hline
\end{tabular}

Table A18: Akaike Information Criterion for the parametric models shown in Figure 2.

\begin{tabular}{ccc}
\hline \hline \multirow{2}{*}{ Number of polynomials } & \multicolumn{2}{c}{ Center-left parties All left-wing parties } \\
\hline One & 126.2104 & 153.0023 \\
Two & 111.2641 & 133.894 \\
Three & 112.4707 & 135.8638 \\
Four & 113.658 & 136.991 \\
\hline \hline
\end{tabular}

Table A19: Akaike Information Criterion for the parametric models shown in Table A4.

\begin{tabular}{cccc}
\hline \hline & Median age & $\begin{array}{c}\text { Percentage of women } \\
\text { AIC }\end{array}$ & Household income \\
\hline Number of polynomials & & 465.5027 & -43.37813 \\
One & 485.8686 & 467.4644 & -40.3126 \\
Two & 488.5027 & 470.5763 & -40.01841 \\
Three & 490.6548 & 472.5131 & -39.98796 \\
Four & 490.6025 & \\
\hline \hline
\end{tabular}

Table A20: Akaike Information Criterion for the parametric models shown in Table A6.

\begin{tabular}{cc}
\hline \hline & Left-right placement of RRPs \\
Number of polynomials & AIC \\
\hline One & 183.766 \\
Two & 186.9333 \\
Three & 189.2645 \\
Four & 191.246 \\
\hline \hline
\end{tabular}

Table A21: Akaike Information Criterion for the parametric model shown in Table A7.

\begin{tabular}{ccc}
\hline \hline & \multicolumn{2}{c}{ Parties not considered RRP by Mudde (2007) } \\
Number of polynomials & \multicolumn{2}{c}{ AIC not considered RRP by Norris (2005) } \\
\hline One & 58.27376 & 48.5861 \\
Two & 61.22519 & 51.79559 \\
Three & 61.90775 & 54.1189 \\
Four & 63.90111 & 55.80608 \\
\hline \hline
\end{tabular}

Table A22: Akaike Information Criterion for the parametric model shown in Table A8. 


\begin{tabular}{cc}
\hline \hline & CSES vote share as dependent variable \\
Number of polynomials & AIC \\
\hline One & 375.2961 \\
Two & 376.8414 \\
Three & 380.5751 \\
Four & 381.7385 \\
\hline \hline
\end{tabular}

Table A23: Akaike Information Criterion for the parametric model shown in Table A9.

\begin{tabular}{cc}
\hline \hline & Using the overall reported vote for RRPs as the dependent variable \\
Number of polynomials & AIC \\
\hline One & 54.03162 \\
Two & 56.87012 \\
Three & 57.03367 \\
Four & 58.97776 \\
\hline \hline
\end{tabular}

Table A24: Akaike Information Criterion for the parametric model shown in Table A10.

\begin{tabular}{cc}
\hline \hline & Models including sum vote share for RRPs as a control \\
Number of polynomials & AIC \\
\hline One & 73.169 \\
Two & 75.611 \\
Three & 76.007 \\
Four & 78.007 \\
\hline \hline
\end{tabular}

Table A25: Akaike Information Criterion for the parametric model shown in Table A11.

\begin{tabular}{cc}
\hline \hline & Using only the most voted RRP in each election \\
Number of polynomials & AIC \\
\hline One & 47.07413 \\
Two & 48.2624 \\
Three & 45.1607 \\
Four & 47.16067 \\
\hline \hline
\end{tabular}

Table A26: Akaike Information Criterion for the parametric model shown in Table A12.

\begin{tabular}{cc}
\hline \hline & Controlling for district magnitude \\
Number of polynomials & AIC \\
\hline One & 32.60196 \\
Two & 36.07242 \\
Three & 38.24494 \\
Four & 40.05411 \\
\hline \hline
\end{tabular}

Table A27: Akaike Information Criterion for the parametric model shown in Table A13. 


\begin{tabular}{cc}
\hline \hline & Models with country fixed effects \\
Number of polynomials & AIC \\
\hline One & 34.2594 \\
Two & 36.94347 \\
Three & 39.69599 \\
Four & 43.5502 \\
\hline \hline
\end{tabular}

Table A28: Akaike Information Criterion for the parametric model shown in Table A14.

\begin{tabular}{cc}
\hline \hline & Models with survey wave fixed effects \\
Number of polynomials & AIC \\
\hline One & 77.84258 \\
Two & 80.0005 \\
Three & 79.52519 \\
Four & 81.52278 \\
\hline \hline
\end{tabular}

Table A29: Akaike Information Criterion for the parametric model shown in Table A15.

\begin{tabular}{cc}
\hline \hline & Models coding AfD as an RRP in 2013 \\
Number of polynomials & AIC \\
\hline One & 73.00369 \\
Two & 75.03942 \\
Three & 76.03478 \\
Four & 78.0273 \\
\hline \hline
\end{tabular}

Table A30: Akaike Information Criterion for the parametric model shown in Table A16. 


\section{B Supporting Materials for Study 2}

Study 2 showed that the difference between how much individuals like parties in private and public modes of interview is reduced when the parties make it to the parliament, but this reduction is larger in the case of RRPs. This appendix provides some complimentary analyses to that study.

To start with, I show analyses that provide some additional detail, by looking at heterogeneous effects based on education. One could expect individuals with higher education to be more affected by the parliamentary entry of an RRP, as they are likely to be more able to perceive what the socially desirable action is in each given context (e.g., Billig 1991). Consequently, these individuals would probably be more affected by the perceived change in strength of social norms provided by the parliamentary entry of an RRP. To check for this effect, I replicate Figure 5 just for RRPs, including an interaction term between the mode of interview, whether the party is in parliament, and a dummy for whether the respondent has a college degree. The results can be found in Figure B1. The Figure shows that, indeed, the effect is larger for individuals with a college degree.

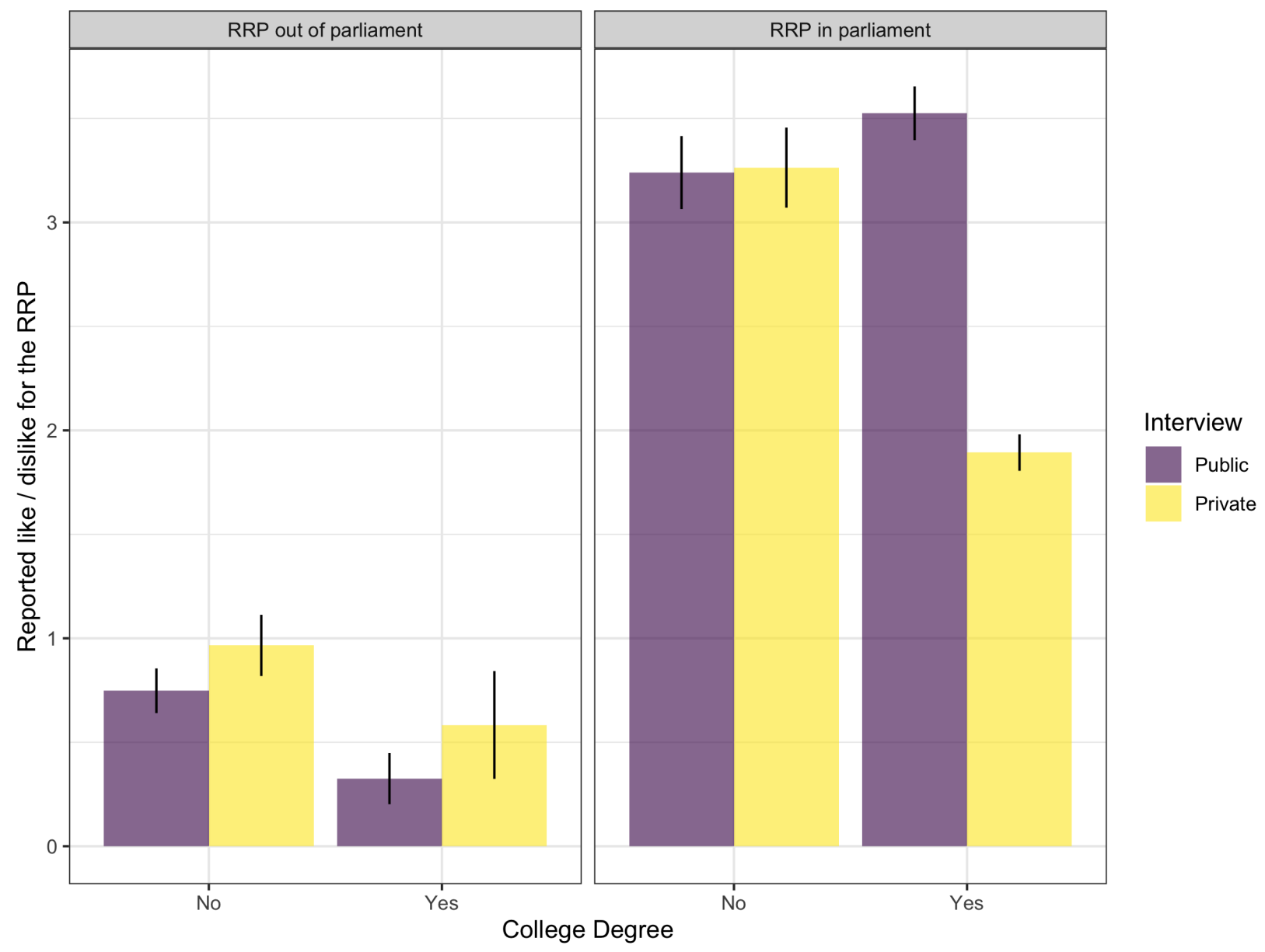

Figure B1: Reported like / dislike for RRPs in and out of parliamentary, by mode of interview and college degree.

Note: Vertical lines represent $95 \%$ confidence intervals. 
Afterwards, I provide some robustness checks for the analyses carried out in this study. One potential criticism is that respondents may not be randomly distributed across the two modes of interview. To make sure that differences in the characteristics of individuals are not driving the results, I replicate the analyses of the regression plotted in 5 , controlling for sociodemographic variables, the vote share of each party, and dummies for the party each respondent had voted for in the previous election. The party voted for in the previous election is arguably a better control variable than each respondent's left-right self-placement because it is less likely to have been affected by the treatment (the parliamentary entry of a radical right party), hence raising less concerns of posttreatment bias. However, to make sure this decision is not affecting the results, I also estimate models that controls for left-right self-placement instead of the dummies for party choice (models 3 and 7). As an alternative way of controlling for differences in the sociodemographic characteristics of respondents, Models 4 and 8 make use of the demographic weights provided in CSES instead of statistical controls.

Another potential problem with these analyses is that they compare radical right parties to all other parties, hence combining parties with different ideologies. For this reason, I estimate the analyses both comparing RRPs to all other parties (Models 1 to 4 ) and comparing RRPs just to center-right parties (Models 5 to 8). The ideology of parties was coded according to their left-right self-placement by country experts, as provided by CSES. Parties were considered to be center-right whenever their expert placement is higher than 5 in a scale from 0 to 10 and were not coded as being radical right. For each of two these samples, I estimate the results with and without demographic weights and the controls discussed above.

The results, presented in Table B1, show that the effects remain very similar after the controls are introduced, after weighting, and regardless of the group of parties to which RRPs are compared. 


\begin{tabular}{|c|c|c|c|c|c|c|c|c|}
\hline & \multicolumn{4}{|c|}{ RRPs vs. all other parties } & \multicolumn{4}{|c|}{ RRPs vs. center-right parties } \\
\hline & $(1)$ & $(2)$ & $(3)$ & $(4)$ & $(5)$ & (6) & $(7)$ & $(8)$ \\
\hline \multirow[t]{3}{*}{ Public } & -0.413 & -0.436 & -0.259 & -0.259 & -0.413 & -0.342 & -0.282 & -0.259 \\
\hline & $(0.093)$ & $(0.108)$ & $(0.115)$ & $(0.115)$ & $(0.093)$ & $(0.112)$ & $(0.103)$ & $(0.115)$ \\
\hline & {$[0.000]$} & {$[0.000]$} & {$[0.024]$} & {$[0.024]$} & {$[0.000]$} & {$[0.002]$} & {$[0.006]$} & {$[0.024]$} \\
\hline \multirow[t]{3}{*}{ Parliament } & 2.521 & 2.358 & 2.647 & 2.647 & 2.831 & 2.805 & 2.234 & 2.941 \\
\hline & $(0.081)$ & $(0.100)$ & $(0.095)$ & $(0.095)$ & $(0.084)$ & $(0.118)$ & $(0.104)$ & $(0.101)$ \\
\hline & {$[0.000]$} & {$[0.000]$} & {$[0.000]$} & $[0.000])$ & {$[0.000]$} & {$[0.000]$} & {$[0.000]$} & {$[0.000]$} \\
\hline \multirow[t]{3}{*}{ Public * Parl } & 0.646 & 0.203 & 0.440 & 0.440 & 0.376 & -0.071 & 0.414 & 0.398 \\
\hline & $(0.097)$ & $(0.113)$ & $(0.123)$ & $(0.123)$ & $(0.102)$ & $(0.129)$ & $(0.117)$ & $(0.132)$ \\
\hline & {$[0.000]$} & {$[0.072]$} & {$[0.000]$} & {$[0.000]$} & {$[0.000]$} & {$[0.584]$} & {$[0.000]$} & [0.003] \\
\hline \multirow[t]{3}{*}{ Radical Right } & -0.462 & -0.494 & -0.410 & -0.410 & -0.462 & -0.503 & -0.425 & -0.410 \\
\hline & $(0.062)$ & $(0.076)$ & $(0.068)$ & $(0.068)$ & $(0.062)$ & $(0.076)$ & $(0.072)$ & $(0.068)$ \\
\hline & {$[0.000]$} & {$[0.000]$} & {$[0.000]$} & {$[0.000]$} & {$[0.000]$} & {$[0.000]$} & {$[0.000]$} & {$[0.000]$} \\
\hline \multirow[t]{3}{*}{ Public * Rad Right } & 0.157 & 0.179 & 0.174 & 0.174 & 0.157 & 0.198 & 0.120 & 0.174 \\
\hline & $(0.075)$ & $(0.088)$ & $(0.096)$ & $(0.096)$ & $(0.075)$ & $(0.088)$ & $(0.085)$ & $(0.096)$ \\
\hline & {$[0.036]$} & {$[0.042]$} & [0.069] & [0.069] & {$[0.036]$} & [0.025] & {$[0.162]$} & [0.069] \\
\hline \multirow[t]{3}{*}{ Parl * Rad Right } & -1.230 & -0.458 & -1.000 & -1.000 & -1.541 & -0.077 & -1.304 & -1.294 \\
\hline & $(0.076)$ & $(0.095)$ & $(0.104)$ & $(0.104)$ & $(0.079)$ & $(0.103)$ & $(0.0 .097)$ & $(0.112)$ \\
\hline & {$[0.000]$} & {$[0.000]$} & {$[0.000]$} & {$[0.000]$} & {$[0.000]$} & {$[0.455]$} & [0.000] & {$[0.000]$} \\
\hline \multirow[t]{3}{*}{ Public * Parl * Rad Right } & 0.876 & 0.810 & 0.873 & 0.479 & 1.147 & 0.773 & 0.905 & 0.521 \\
\hline & $(0.101)$ & $(0.126)$ & $(0.116)$ & $(0.146)$ & $(0.106)$ & $(0.128)$ & $(0.122)$ & $(0.158)$ \\
\hline & {$[0.000]$} & {$[0.000]$} & {$[0.000]$} & {$[0.001]$} & {$[0.000]$} & {$[0.000]$} & {$[0.000]$} & {$[0.001]$} \\
\hline \multicolumn{9}{|l|}{ Control Variables } \\
\hline \multirow[t]{3}{*}{ Age } & & -0.001 & -0.002 & & & -0.002 & -0.003 & \\
\hline & & $(0.001)$ & $(0.001)$ & & & $(0.001)$ & $(0.001)$ & \\
\hline & & {$[0.277]$} & {$[0.027]$} & & & {$[0.141]$} & [0.079] & \\
\hline \multirow[t]{3}{*}{ Dummy Female } & & 0.006 & 0.121 & & & -0.140 & -0.075 & \\
\hline & & $(0.031)$ & $(0.033)$ & & & $(0.041)$ & $(0.045)$ & \\
\hline & & {$[0.842]$} & {$[0.000]$} & & & {$[0.001]$} & [0.095] & \\
\hline \multirow[t]{3}{*}{ Household Income } & & 0.009 & 0.048 & & & -0.013 & 0.009 & \\
\hline & & $(0.012)$ & $(0.012)$ & & & $(0.015)$ & $(0.017)$ & \\
\hline & & {$[0.491]$} & {$[0.000]$} & & & [0.413] & {$[0.576]$} & \\
\hline \multirow[t]{3}{*}{ Left-right } & & & 0.117 & & & & 0.422 & \\
\hline & & & $(0.007)$ & & & & $(0.010)$ & \\
\hline & & & {$[0.000]$} & & & & {$[0.000]$} & \\
\hline \multirow[t]{3}{*}{ Party vote share } & & 0.055 & 0.053 & & & -0.045 & 0.023 & \\
\hline & & $(0.001)$ & $(0.001)$ & & & $(0.002)$ & $(0.002)$ & \\
\hline & & {$[0.000]$} & {$[0.000]$} & & & {$[0.000]$} & [0.000] & \\
\hline Dummies party choice & $\mathrm{NO}$ & YES & NO & $\mathrm{NO}$ & $\mathrm{NO}$ & YES & $\mathrm{NO}$ & NO \\
\hline Demographic weights & $\mathrm{NO}$ & NO & NO & YES & NO & NO & NO & YES \\
\hline \multirow[t]{3}{*}{ Constant } & 1.35 & 1.257 & 1.246 & 1.246 & 1.350 & 0.630 & -0.406 & 1.246 \\
\hline & $(0.078)$ & $(0.115)$ & $(0.088)$ & $(0.088)$ & $(0.078)$ & $(0.133)$ & $(0.128)$ & $(0.088)$ \\
\hline & {$[0.000]$} & {$[0.000]$} & {$[0.000]$} & {$[0.000]$} & {$[0.000]$} & {$[0.000]$} & {$[0.002]$} & {$[0.000]$} \\
\hline$N$ & 65,505 & 43,994 & 50,254 & 65,505 & 32,813 & 22,755 & 25,873 & 32,813 \\
\hline Clusters (individuals) & 9,340 & 6,250 & 7,223 & 9,340 & 9,280 & 6,225 & 7,194 & 9,280 \\
\hline
\end{tabular}

Standard errors in parentheses; $p$-values in brackets.

Standard errors are clustered by individual.

Table B1: Effect of radical right, presence of the party in the parliament and mode of interview on reported like / dislike for a party. 


\section{Supporting Materials for Study 3}

As with the RDD in Study 1, one possible objection to Study 3 is that, after the parliamentary entry of UKIP, the set of voters who reported having voted for it had different characteristics. To check for this possibility, I test for differences in the sociodemographic characteristics of individuals who reported to have voted for the party following the election of 2010 and following the election of 2015. To do so, I merge the data from the BES 2010 and 2015 and create a dummy variable coded 1 for individuals interviewed after the election of 2015 and 0 for individuals interviewed after the election of 2010. Then, I regress respondents' age, gender, and a dummy for high income ${ }^{13}$ on that variable. The results are shown in Figure $\mathrm{C} 1$. The coefficients are all small and fail to reach traditional thresholds of statistical significance.

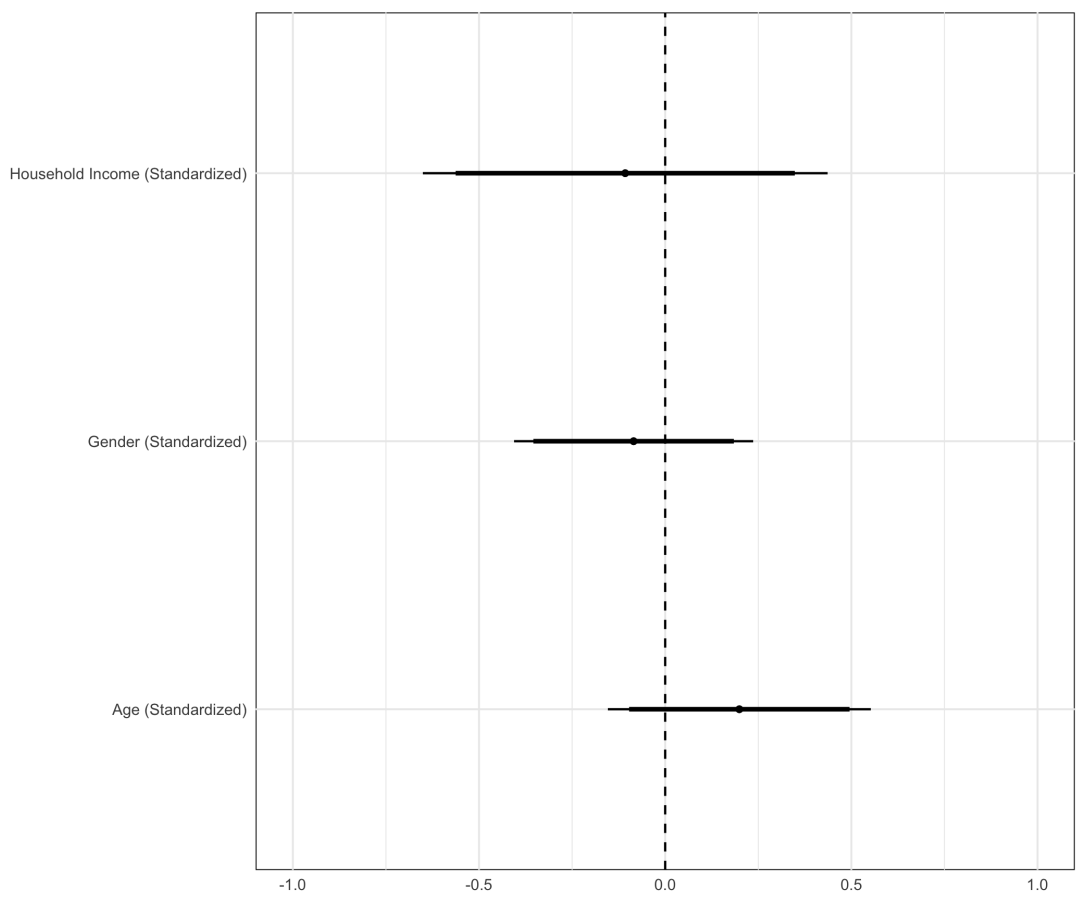

Figure C1: Differences in the sociodemographic characteristics of UKIP votes in 2010 and 2015 .

Note: Thin represent 95\% confidence intervals; thick bars represent $90 \%$ confidence intervals. Standard errors are robust.

As a further robustness check, I look at whether the estimates are very sensitive to changing the parties that are included in the control group. To do so, I replicate the models in Figure 7, with the exception of the placebo, using all possible combinations of

\footnotetext{
${ }^{13}$ Household income is coded differently in the 2010 and 2015 versions of the BES. Because the income associated with each category does not match in each year, I recoded the variable as a dummy for high income. This variable was coded 1 for respondents earning more than 50,000 pounds and 0 for respondents earning less. Despite differences in other categories, this cutoff exists in both versions of the BES.
} 
the three main parties as a control group: the three parties at once, each party individually, and each possible pair of parties. This results in a total of seven possible controls and 21 models. Figure $\mathrm{C} 2$ plots the coefficient size obtained in this test. All coefficients are clearly above 0 . Their mean is 0.213 and their median is 0.230 - which is very close to the effect sizes reported in Figure 7.

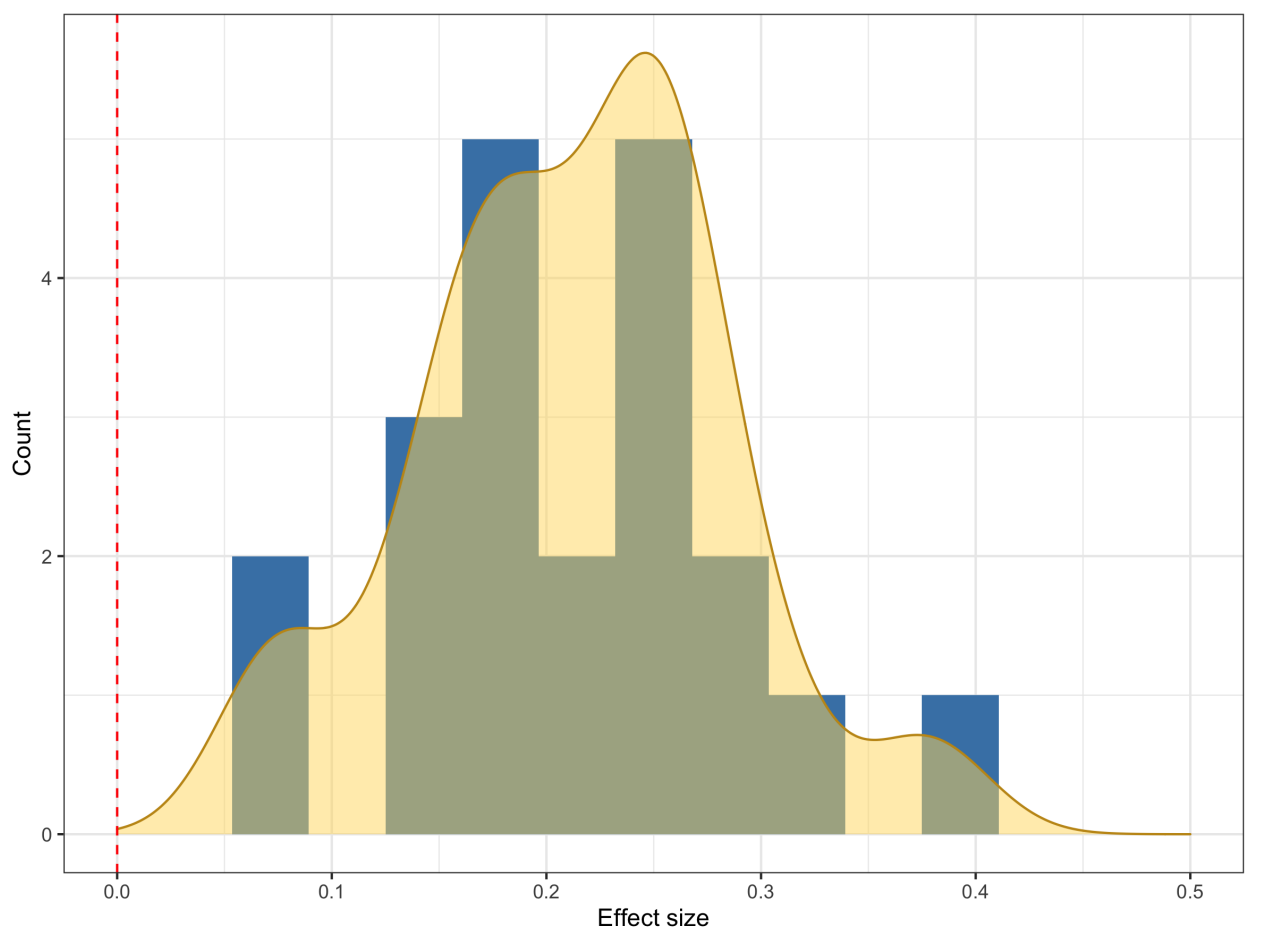

Figure C2: Coefficient sizes obtained from 21 replications of the analyses in Figure 7 using all possible combinations of parties as control group.

The analyses shown in Figure 7 include the three main UK parties in the control group. Figure C3 shows parallel trends plots similar to that in Figure 7 comparing UKIP to each of the parties in the control group individually: LibDem, Conservatives, and Labour. These plots suggest that, within these three control groups, the parallel trends assumption is met best when comparing UKIP to LibDem. However, all three plots suggest that, in 2015, the proportion of the official vote for UKIP that was reported in post-electoral surveys increased when compared to the remaining parties. It should be noted that these analyses comparing UKIp to a single party do not provide enough degrees of freedom to calculate confidence intervals, which is why I report only the parallel trends plots. 

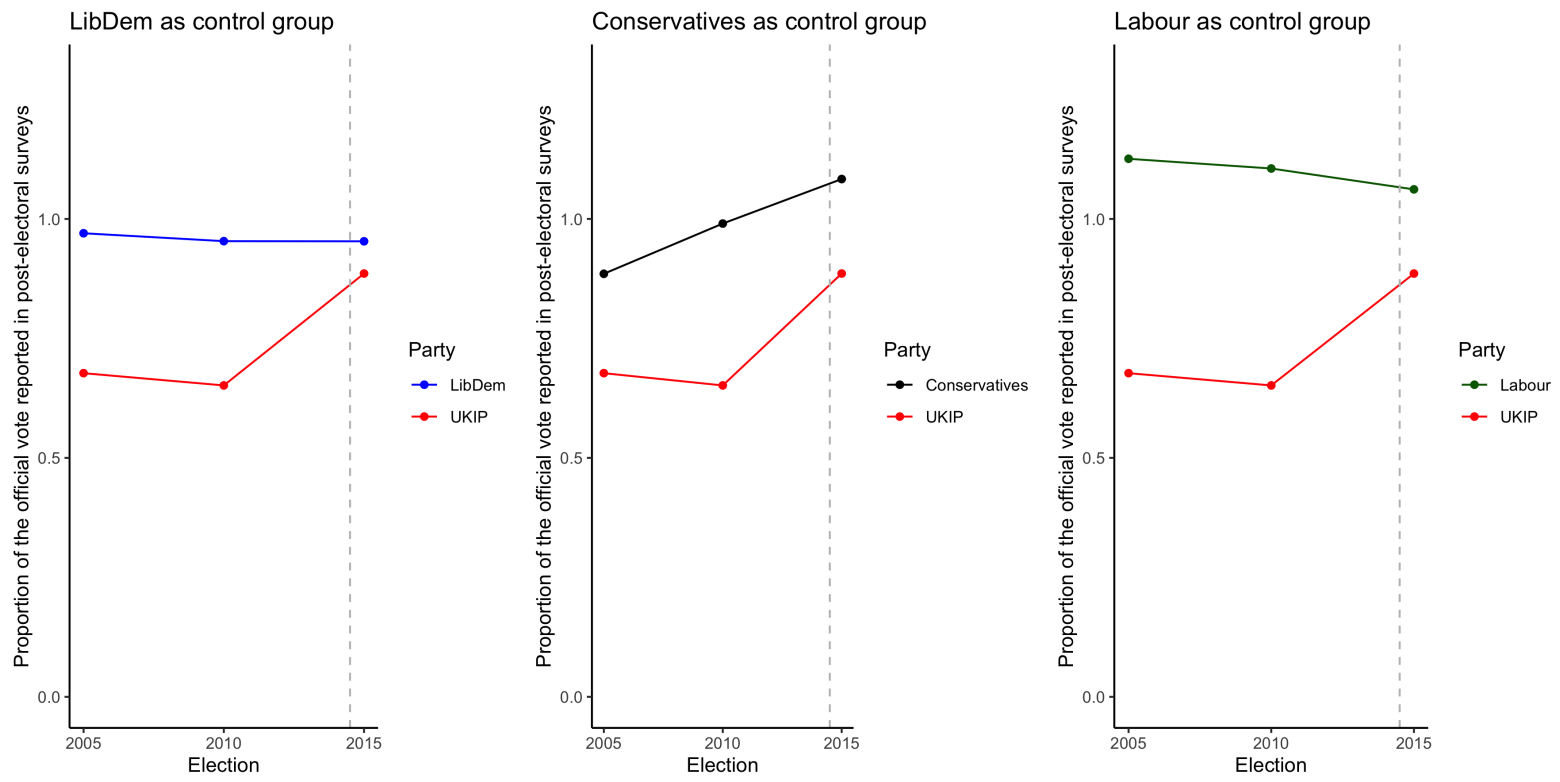

Figure C3: Parallel trends plots comparing UKIP to each of three control parties individually. 